Journal of Thermal Engineering, Vol. 5, No. 4, pp. 251-270, July, 2019

Yildiz Technical University Press, Istanbul, Turkey

\title{
DETERMINATION OF SOME DOMESTIC RADIATORS' THERMAL CAPACITY NUMERICALLY
}

\author{
A. S. Dalkilic ${ }^{1, *}$, O. Acikgoz ${ }^{1}$, E. Ekici ${ }^{1}$, S. Wongwises ${ }^{2}$
}

\begin{abstract}
Free convection and radiation comprise the heat transfer mechanisms through which a hydronic household radiator conveys heat from its surface to air and surrounding surfaces. It should also be noted that their performance could be enhanced by improving surface geometries as well as increasing temperature levels. In the present study, heat transfer rates and convective heat transfer coefficients occurring through the investigated radiators, were numerically examined. To this end, radiators at two different dimensions having two different geometric shapes were drawn and analyzed in the program Ansys 17. The heat transfer rates obtained from the program were validated via radiator producer catalogues. Furthermore, the influence of parameters, such as water velocity in the radiators and thus mass flow rate, temperature difference between water inlet and outlet and also between radiator surface and surrounding air on convective heat transfer coefficient over radiator, were scrutinized.
\end{abstract}

\section{Keywords: Radiator, Heat Transfer, Natural Convection, Radiation, ANSYS}

\section{INTRODUCTION}

In today's world energy economy agenda, high energy consumption in buildings, has accounted for the requirement for emerging low-temperature heating devices both in new and old ones. Also, energy saving can be achieved by diminishing supply temperatures and radiant panel heating systems that encompass floor heating, ceiling heating and wall heating in central heating systems.

Nonetheless, improving the performance of central heating in buildings has a significant effect on energy savings, as well. Furthermore, heating by radiators has still been the most prevalent technique for domestic and industrial applications in the world. In the usual design of radiators, the hot water is circulated in the narrow radiator channel and heat is conveyed to the ambient air, and the circulated water in the radiator leaves at a lower temperature. Convectors support to rise the heat transfer from the radiators. Computational Fluid Dynamics (CFD) is one of the significant technique to design and improve the performance of the radiator numerically.

Improving the heat capacity of hydronic central heating systems in buildings can be the core point in terms of energy saving. Existing radiators of these systems have working conditions at constant flow plan with thermostat control device mostly. This sort of operating mode may not be evaluated efficient with regard to energy consumption and thus other working scenarios are necessary to improve the heat capacity of the radiators. Given the issues relevant to having better thermal efficiency from radiators, the literature have been thoroughly reviewed and presented in the following paragraphs.

By means of a particle image velocimetry along with a computational fluid dynamics approach, Calisir et al. [1] analyzed the flow of the air over a panel radiator. The inlet and outlet temperatures of the radiator were selected as $75^{\circ} \mathrm{C}$ and $65^{\circ} \mathrm{C}$, respectively. Experiments were carried out on a radiator of which dimensions were $600 \times 1000 \mathrm{~mm}$, under a stable laboratory environment with a room temperature of $20^{\circ} \mathrm{C}$. In conclusion, at discrete parts of the radiator, velocity distribution was obtained and figured out that a non-symmetrical velocity distribution took place over the radiator.

This paper was recommended for publication in revised form by Regional Editor Bekir Yilbas

${ }^{I}$ Department of Mechanical Engineering, Ylldiz Technical University, İstanbul, Turkey

${ }^{2}$ Department of Mechanical Engineering, King Mongkut's University of Technology and Thonburi, Bangkok, Thailand

*Corresponding Author: dalkilic@yildiz.edu.tr

Orcid id: 0000-0002-5743-3937, 0000-0002-0095-829X, 0000-0002-6000-2863, 0000-0003-2648-6814

Manuscript Received 10 October 2017, Accepted 17 December 2017 
Embaye et al. [2] aimed to study the influence of panel radiator under pulsed flow conditions in order to have indoor spatial temperature and velocity distributions. They stated that they have succeed energy saving with thermal comfort given by international standards. They benefitted from CFD technique for constant and pulsed flows and validated their results with data in open sources.

Ludumor et al. [3] reviewed automotive engine cooling systems indicating the importance of engine surface temperature regarding with the engine ideal efficiency. They have given latest information on forced engine cooling systems to progress new approaches to increase its efficiency. Parameters affecting the radiator performance from the experimental and numerical works have been summarized briefly.

Calisir et al. [4] aimed to see the influences of the sizes of convectors on heat transfer mainly. Initially, the current convector sizes used in a produced radiator were applied in the code of simulation work. Then, the influences of various sizes about the heat transfer were studied. The primary aim of their work was to investigate an optimum arrangement to have the maximum heat output. The space between two convectors, dimension of the base of the convectors and their tip width was examined, and the maximum heat transfer was achieved for $6.31 \mathrm{~mm}, 4 \mathrm{~mm}$ and $12 \mathrm{~mm}$, correspondingly. It was detected that decreasing the convector height and length has an increasing influence about heat transfer performance. A slight rise in heat transfer was obtained with rising convector thickness, and space between two opposite fins improved the heat transfer to a specified value.

Kayastha [5] used a 55 HP engine radiator data for the numerical analysis. He prepared a model in Pro-E software and solved it in ANSYS-12. Two different pitches around $15 \mathrm{~mm}$ and $20 \mathrm{~mm}$ are used for helical tubes in the radiator. The comparison is completed for dissimilar mass flow rates in helical type tubes. According to the analyses, maximum temperature drop and minimum pressure drop happen at the mass flow rate of $0.5 \mathrm{~kg} / \mathrm{sec}$. It is determined that there is increase in temperature drop and decrease in pressure drop with decreased mass flow rate.

Embaye et al. [6] focused on the effect of pulsed flow parameter on the energy consumption of panel radiators. They modeled two hydronic panel radiators with constant and pulsating flows by CFD technique using the conjugate heat transfer in COMSOL Multiphysics program. The tested radiators were one with single finned surface and one without fins, their sizes were $500 \mathrm{~mm}$ long and $300 \mathrm{~mm}$ high. They validated their CFD model of the constant flow ones with experimental data in literature successfully. Then, they stated that their simulation results of pulsed flow conditions can decrease the energy consumption of panel radiators in comparison to constant flow ones.

Johansson and Wollerstrand [7] studied on the increase of convection in order to have larger heat output. Their numerical works include the comparison of standard panel radiators with and without add-on-fan blower. They prepared their model by COMSOL software using a 2D-model and the multi physic mode. They tested their model at different temperature levels in the radiator, and at different fan speeds. They aimed to derive new temperature software for the radiator at various fan speeds.

Shi et al. [8] indicated the significance of the optimum design of plate-type radiators. They tried to change the shape of the radiator. They obtained larger efficiencies with the angles of $13-20^{\circ}$ for inlet sides of ducts. Their study includes not only numerical simulations, but also it has experimental parts.

Myhren and Holmberg [9] focused on radiator heat output and comfort temperatures in a small office room. They have made tests using different positions for the ventilation air inlet. Their numerical works were performed by CFD software's simulations including visualization of thermal comfort situations. Their conclusions indicated that more stable thermal climate conditions can be obtained by ventilation-radiators under used parameters than the traditional ones. Moreover, they obtained lower radiator surface temperatures by the use of ventilation-radiators and thus energy and environmental savings were able to be obtained.

Sarbu and Sebarchievici [10] studied the thermal performance of various kinds of low temperature heating systems both experimentally and numerically. They compared the heat capacity and comfort of radiator and radiant floor heating systems joined to a ground-coupled heat pump. They prepared a mathematical model with the validation process for the numerical analyses of radiant floors. Furthermore, their comparison work included the energy, environmental and economic performances of floor, wall, ceiling and floor-ceiling heating. They concluded that floorceiling heating systems were better than other low-temperature ones relating with having better thermal comfort, lower energy consumption, lower $\mathrm{CO}_{2}$ emission and lower operating cost. 
Aydar and Ekmekci [11] have examined panel radiators in Turkey through CFD codes in three dimensional spaces. They acquired numerical efficiency data and afterward the data were compared with extant catalogue values of panel radiators. Optimum air-side convective heat transfer value was found and as a result of that, computational calculations were carried out in accordance with the determined value.

Chacko et al. [12] issued the airflow distribution in the radiator cover using CFD techniques. A remarkable number of optimization case studies were conducted to determine the optimum configuration of the radiator cover. CFD studies compared with test data have demonstrated that notable fields of re-circulation flows are present in the radiator cover. The optimization provided by means of the CFD work has ensured those recirculation regions to be averted and have augmented the flow within the radiator around $34 \%$.

Sevilgen and Kilic [13] implemented a numerical investigation within a room heated through two radiators, while a virtual manikin having actual dimensions as well as physical shape similar to a real person was sitting. In conclusion, the authors have determined heat interaction between the surfaces of the manikin and the room environment, the local heat transfer coefficients of the manikin and the surroundings etc.

Shati et al. [14] have examined the influence of emissivity and roughness of the surface behind a radiator over the thermal output of the radiator. The numerically and experimentally obtained data have shown that the presence of large scale surface roughness and a high emissivity value enhance not only the heat output, but also the air velocity behind the radiator if it is compared to a smooth surface. The data also demonstrate that the heat transfer may be augmented approximately $26 \%$ using a high emissivity saw tooth surface.

Arslanturk and Ozguc [15] developed an analytical model to assess the optimum dimensions of a central heating radiator. They have calculated the optimum geometry that maximizes the heat transfer rate as well as the geometrical limits relevant with manufacturing techniques. Also, the influences of geometrical and thermal parameters over the radiator's efficiency were given.

Menendez-Diaz et al. [16] investigated stoneware panel coverings which are claimed that they enhance the thermal efficiency of radiators. To implement this aim, they carried out a theoretical and experimental work. The results have indicated that within the cooling period, the stoneware panel temperature is a little higher than the corresponding temperature of the aluminum radiator surface of the radiator. Nonetheless, aftermath of the start of cooling, this difference has a tendency to vanish. After 50 minutes cooling has started, the difference was found lower than $2^{\circ} \mathrm{C}$.

Brady et al. [17] studied the effect of magnetic decorative covers on the heat output from a radiator. A significant number of case studies were conducted and the heat output a bare radiator was compared with a radiator applied under a magnetic cover, and within a wooden cover. The obtained results have indicated that magnetically applied radiator has a higher efficiency roughly $13-20 \%$, compared to traditional radiator wooden cover.

Kılıç et al. [18] have utilized a CFD approach in order to do the thermal analysis of a steel panel radiator. The study was done according to TS EN442, and the CFD application was executed using finite volume method. It should also be noted that the case studies were implemented under steady-state conditions. As a result, it has been observed that the acquired numerical data are consistent with the relevant experimental data in the literature.

By means of a 3D finite volume CFD code, Jahanbin and Zanchini [19] examined the performance of a thin plane radiator in a real-size room. The case studies they carried out were verified by comparing the mean Nusselt number on the radiator surface with the one attained through the equations derived by some other researchers' in the literature. Using the code, the temperature and velocity fields within the enclosure, the total output of the radiator and the operative temperature have been obtained. As a conclusion, it was understood that a range of $10 \mathrm{~cm}$ between radiator and wall provided a small enhancement in air movements within the room.

Beck et al. [20] worked on the effect of wall emissivity behind panel radiators over the heat output. The study was implemented by means of both experimental and numerical methods. The results indicate that the heat transfer can be augmented roughly $20 \%$ with the usage of a black wall, instead of a reflective wall. In addition to this, it was stated that the output of single plate radiator would be enhanced approximately $10 \%$ and a double radiator roughly $5 \%$. 
Furthermore, in his articles Khalifa [21, 22] have scrutinized and presented the convective heat transfer correlations derived by numerous researchers which were found for vertical and horizontal free plates, alongside for enclosures heated through various methods. It should be noted that in the present study, the correlations cited by Khalifa [21, 22] have been selected to compare the results of this study with data in the literature. The correlations chosen, the researchers by whom derived and the conditions they are accurate are presented in Tables 1 and 2.

In case the relevant literature is rigorously scrutinized, it can easily be understood that there has been a significant uninvestigated field regarding household radiators issue. Thus, the influence of numerous parameters that have effects on heat transfer through the radiators, and the convective heat transfer coefficient arising over the radiators have been scrutinized, in the current work. Parameters such as temperature differences at air and water sides, water velocity and mass flow rate were taken in consideration on the calculation of heat output of the tested radiators, and on the convective heat transfer coefficients occurring over them. Moreover, the main purpose of this computational study is to demonstrate the likelihood of validation process of household radiators by means of experimental data, to provide visual clarifications and to produce various outputs using Ansys software's results. The methods of numerically solving this issue and accomplishing this aim consist of examining the internal and external fluid flow of the radiator and then comparing these outputs to the experimental data of a radiator producer company.

\section{NUMERICAL METHOD}

Due to long lasting of solution periods, CFD programs were not highly preferable in recent years. Nevertheless, continuously progressing computer processors, in these days allow researchers and building simulators avail themselves of CFD programs in heat transfer applications for heat transfer applications in simulations, such as the radiator systems which consist of different radiator geometries such as in this study. This work, comprised of a broad range of results obtained through varying a number of parameters contains CFD outcomes. To solve the governing equations (continuity, momentum, energy) the CFD program ANSYS 17, which involves FLUENT 17 within, has been preferred. It should also be noted that the outline of the program's solution path is built over the control volume theory through altering relevant equations into algebraic equations for them to be solved. Techniques of control volume are executed by carrying out the integration of the relevant equations on the individual control volume and generating discretization of the equations [23].

One should first be aware of the fact that, to initiate a numerical process, it is significant to separate the given, known data from the unknown one. All sizes for tested radiators are known from producer company's catalogs. The mass flow rates of water regarding the experimental thermal capacities and temperature levels are known. The inlet temperatures for water are taken from catalogs as $75{ }^{\circ} \mathrm{C}$ and $90{ }^{\circ} \mathrm{C}$ and ambient temperatures varied from $10{ }^{\circ} \mathrm{C}$ to $26{ }^{\circ} \mathrm{C}$. The whole numerical process starts with the draw in SolidWorks. Some preferences and automatically determined parameters within the program can be summarized in the following paragraphs:

Among from 5 different size functions, "curvature" has been chosen. Corresponding to Smoothing, Transition, Growth rate options; Medium, Slow and 1.2 selections were made, respectively. Also, minimum edge length of the meshes was $3 \times 10^{-2}$. In addition to this, Transition ratio and Maximum layer values have been determined as 0.272 and 5, respectively. As statistical values, it should be noted that 10895 nodes and 46193 elements occurred within the body of the radiator. A gravitational force value at -y direction has been input as $9.81 \mathrm{~m} / \mathrm{s}^{2}$.

In ANSYS a meshed images of the radiators examined are shown in Figure 1. The next stage is about the entering boundary conditions as water flow velocity, water inlet temperature, ambient temperature and pressure outlet in order to calculate heat transfer rate, surface temperature of the radiator, water outlet temperature, convective heat transfer coefficient of air side, and temperature distribution in the radiator. From this information, it is clear that there are many unknowns for the system. The experimental heat transfer amount is predicted by means of the numerical model in ANSYS 17 of which solution steps are detailed in this section. Some of the obtained numerical results can be seen in Tables 3 and 4 for $900 \mathrm{~mm} / 160 \mathrm{~mm}$ and $500 \mathrm{~mm} / 160 \mathrm{~mm}$ radiators' $75{ }^{\circ} \mathrm{C} / 65^{\circ} \mathrm{C}$ and $90{ }^{\circ} \mathrm{C} / 70{ }^{\circ} \mathrm{C}$ operating conditions, respectively. 
Table 1. The correlations presented Khalifa [21] derived for vertical free plates

\begin{tabular}{|l|l|l|}
\hline Researchers & Conditions & Equation \\
\hline Churchill and Chu & Range applicable in buildings & $\boldsymbol{h}=\left[\mathbf{0 . 1 3 4}(L)^{-\frac{1}{2}}+\mathbf{1 . 1 1}(\Delta T)^{\frac{1}{6}}\right]^{2}$ \\
\hline Alamdari and Hammond & Rayleigh range: $10^{4}-10^{12}$ & $\boldsymbol{h}=\left\{\left[\mathbf{1 . 5}\left(\frac{\Delta T}{\boldsymbol{L}}\right)^{\mathbf{1 / 4}}\right]+\left[\mathbf{1 . 2 3}(\Delta T)^{\frac{1}{3}}\right]^{6^{6}}\right\}^{\frac{1}{6}}$ \\
\hline Fishenden and Saunders & Laminar flow & $\boldsymbol{h}=\mathbf{1 . 3 6 8}(\Delta T / L)^{1 / 4}$ \\
\hline Fishenden and Saunders & Turbulent flow & $\boldsymbol{h}=\mathbf{1 . 9 7 3}(\Delta T)^{1 / 4}$ \\
\hline Griffiths and Davis & $\begin{array}{l}\text { For 1.2 m square plate, up to } \\
100^{\circ} \mathrm{C} \text { temperature difference }\end{array}$ & $\boldsymbol{h}=\mathbf{1 . 7 7 6}(\Delta T)^{1 / 4}$ \\
\hline Heilman & Discs up to 0.25 diameter & $\boldsymbol{h}=\mathbf{1 . 6 6 4}(\Delta T)^{0.27}$ \\
\hline King & $\begin{array}{l}\text { Correlated data from other } \\
\text { researchers }\end{array}$ & $\boldsymbol{h}=\mathbf{1 . 5 1 7}(\Delta T)^{0.33}$ \\
\hline Hottinger & No note available & $\boldsymbol{h}=\mathbf{2 . 5}(\Delta T)^{1 / 4}$ \\
\hline Wilkes and Peterson & $\begin{array}{l}\text { Two heated plates 2.4 } \mathrm{x} 0.8 \mathrm{~m}^{2} \\
\text { with 0.1 m air space }\end{array}$ & $\boldsymbol{h}=\mathbf{3 . 0 5}(\Delta T)^{0.12}$ \\
\hline ASHRAE & For laminar flow & $\boldsymbol{h}=\mathbf{1 . 4 2}(\Delta T)^{1 / 4}$ \\
\hline ASHRAE & For laminar flow & $\boldsymbol{h}=\mathbf{1 . 3 1}(\Delta T)^{1 / 3}$ \\
\hline McAdams & For laminar flow & $\boldsymbol{h}=\mathbf{1 . 4 2}(\Delta T)^{1 / 4}$ \\
\hline
\end{tabular}

Table 2. The correlations presented Khalifa [22] derived for enclosures heated through different surfaces

\begin{tabular}{|l|l|l|}
\hline Researchers & Conditions & Equation \\
\hline Min et al. (heated floor) & Ra range: $10^{9}-10^{11}$ & $\boldsymbol{h}=\mathbf{2 . 4 1 6}(\Delta T)^{0.31} / \boldsymbol{D}_{\mathrm{e}}^{0.08}$ \\
\hline Min et al. (vertical wall) & Ra range: $10^{9}-10^{11}$ & $\boldsymbol{h}=\mathbf{1 . 8 7 3}(\Delta T)^{0.32} / \boldsymbol{H}^{0.05}$ \\
\hline Min et al. (heated ceiling) & Ra range: $10^{9}-10^{11}$ & $\boldsymbol{h}=\mathbf{4 . 6 2 2}(\Delta T)^{0.05} / \boldsymbol{H}^{0.85}$ \\
\hline Li et al. & $\begin{array}{l}\text { An occupied office room at } \\
\text { working conditions }\end{array}$ & $\boldsymbol{h}=\mathbf{2 . 8 8}(\Delta T)^{0.25}$ \\
\hline Khalifa and Marshall & On vertical wall & $\boldsymbol{h}=\mathbf{2 . 3 0}(\Delta T)^{0.23}$ \\
\hline
\end{tabular}

Using the program ANSYS FLUENT 17, a laminar model has been selected owing to entire found Rayleigh number values to be smaller than $10^{9}$. Also, a steady state solution approach has been seen appropriate. In addition, in order to solve the equations with a high precision, the second order upwind scheme has been chosen to discrete them. The under relaxation factors corresponding to pressure, density, body forces, momentum and energy have been selected $0.3,1,1,0.7$ and 0.9 , respectively. The necessary time for each case study to converge at the solution was approximately 2 hours.

The residuals for momentum and continuity equations were determined as $10^{-3}$, while the value was $10^{-6}$ for energy equation. Furthermore, thermo-physical properties of the room air have been calculated at the mean surface temperature of surfaces in each case study, through the tables given by Incropera and DeWitt [24]. Moreover, between two solvers presented by FLUENT, pressure based coupled solver along with a SIMPLE scheme have been selected. 


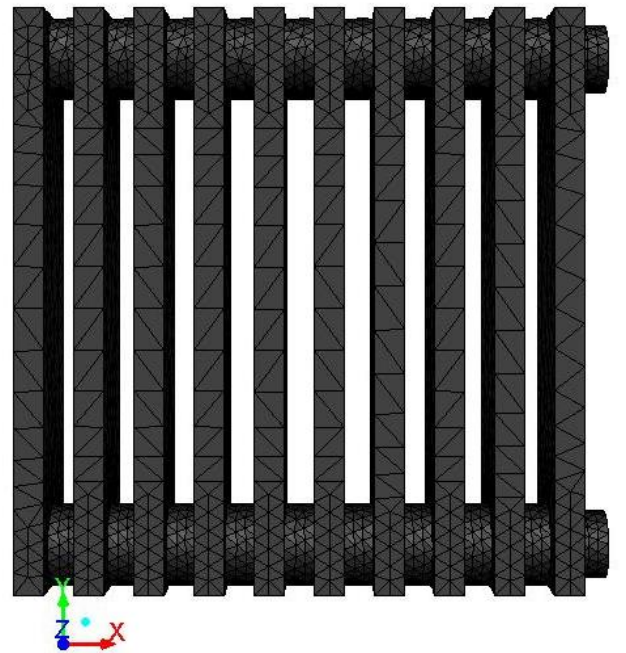

(a)

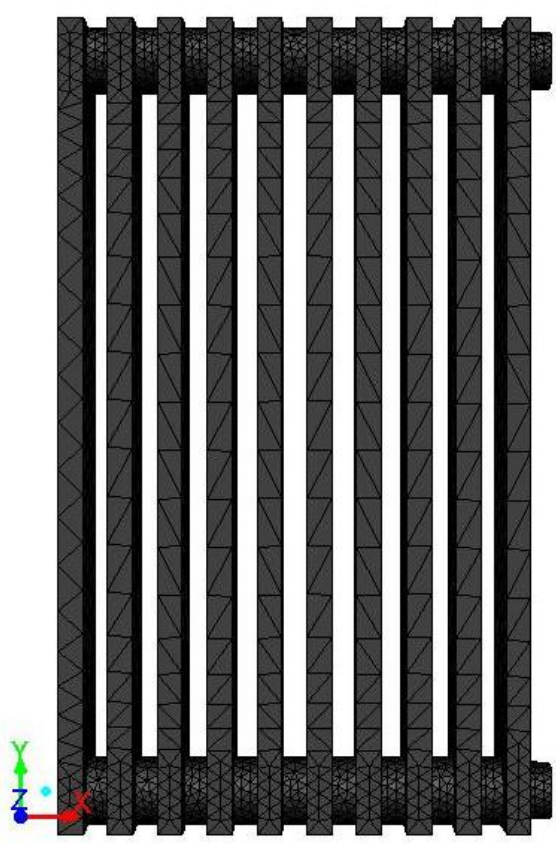

(b)

Figure 1. Cornered end radiators used in analyses (a) $500 \mathrm{~mm}-160 \mathrm{~mm}$, (b) $900 \mathrm{~mm}-160 \mathrm{~mm}$

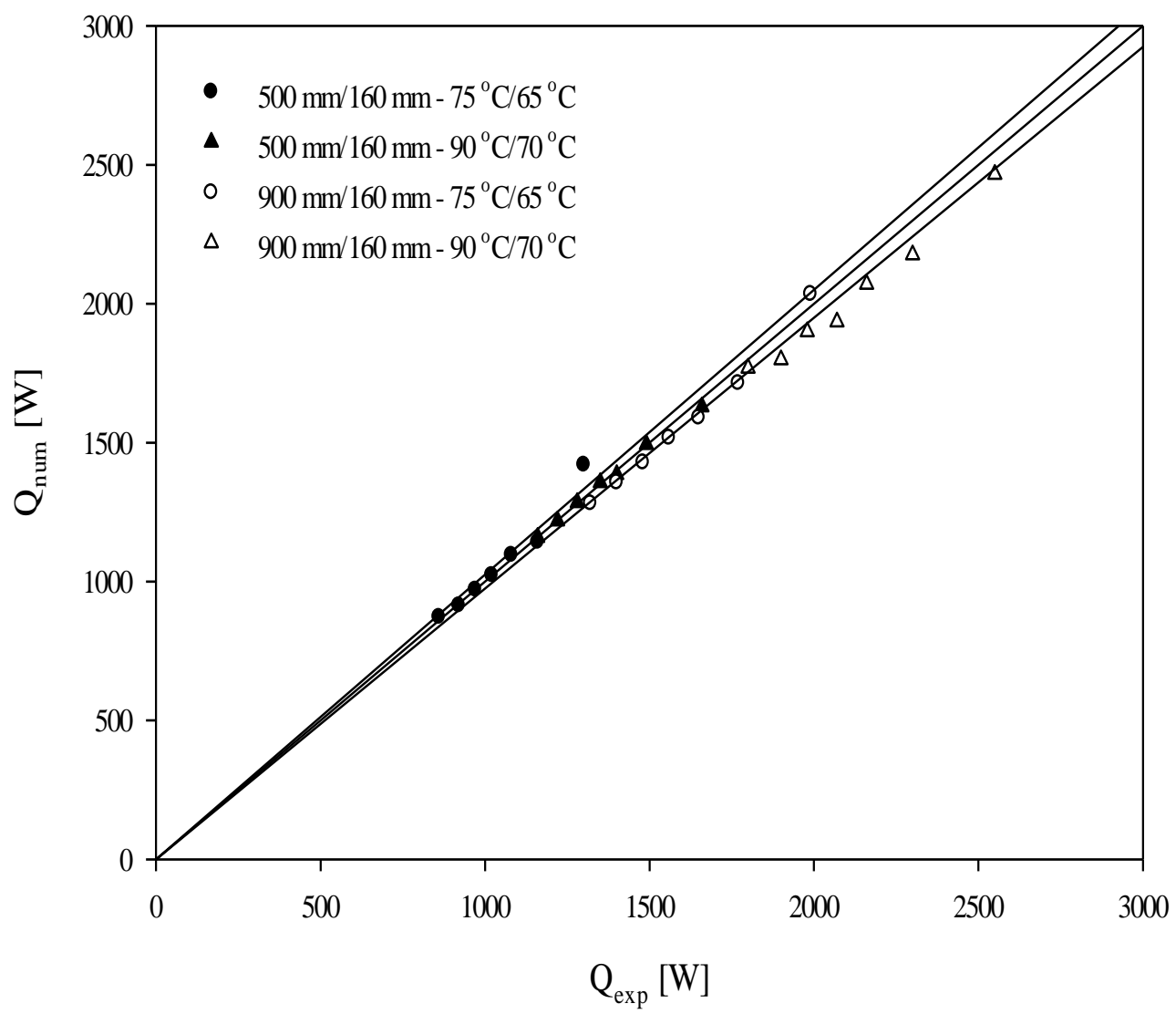

(a) 
Journal of Thermal Engineering, Research Article, Vol. 5, No. 4, pp. 251-270, July, 2019

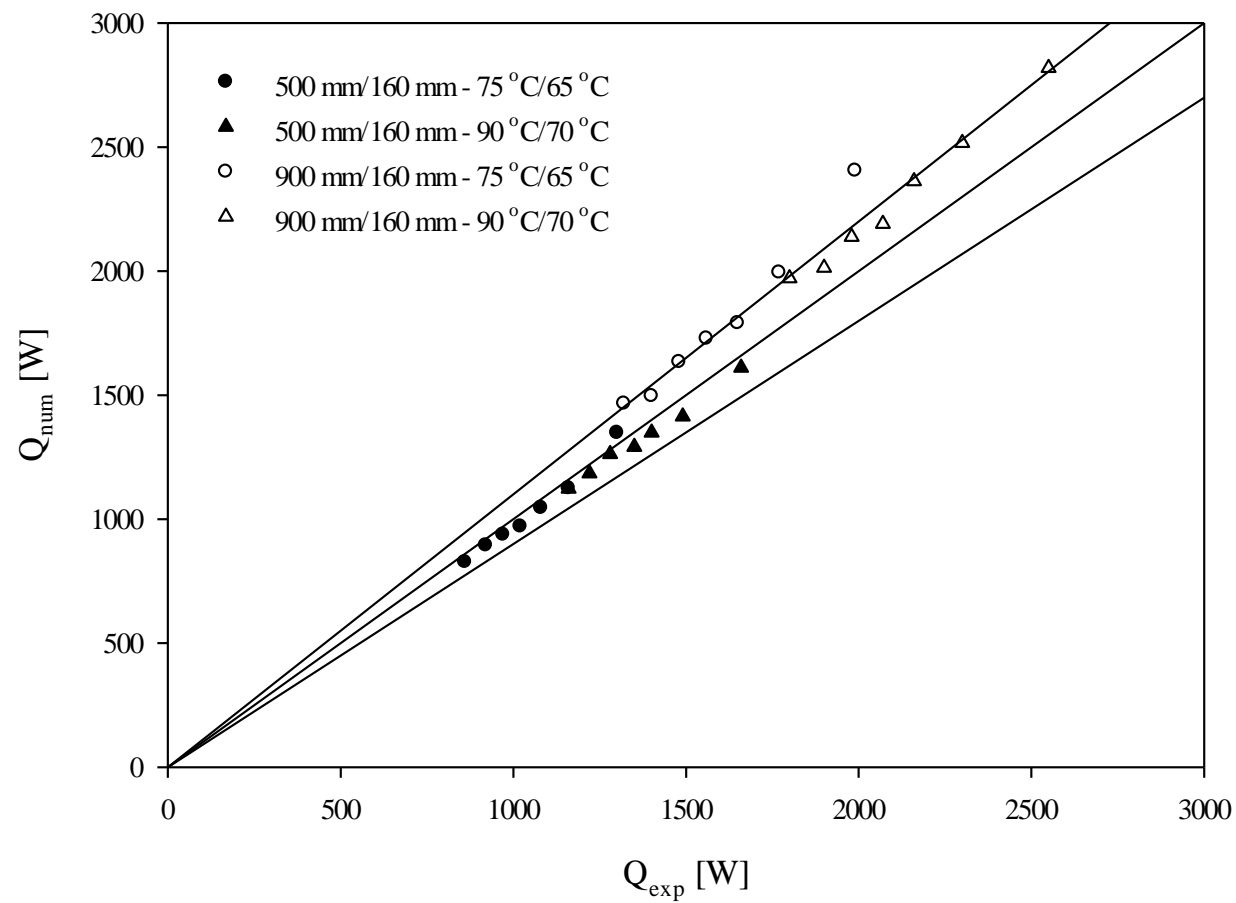

(b)

Figure 2. Comparison between the ANSYS total heat transfer values and experimental data (a) for cornered end, (b) for chamfered end radiators

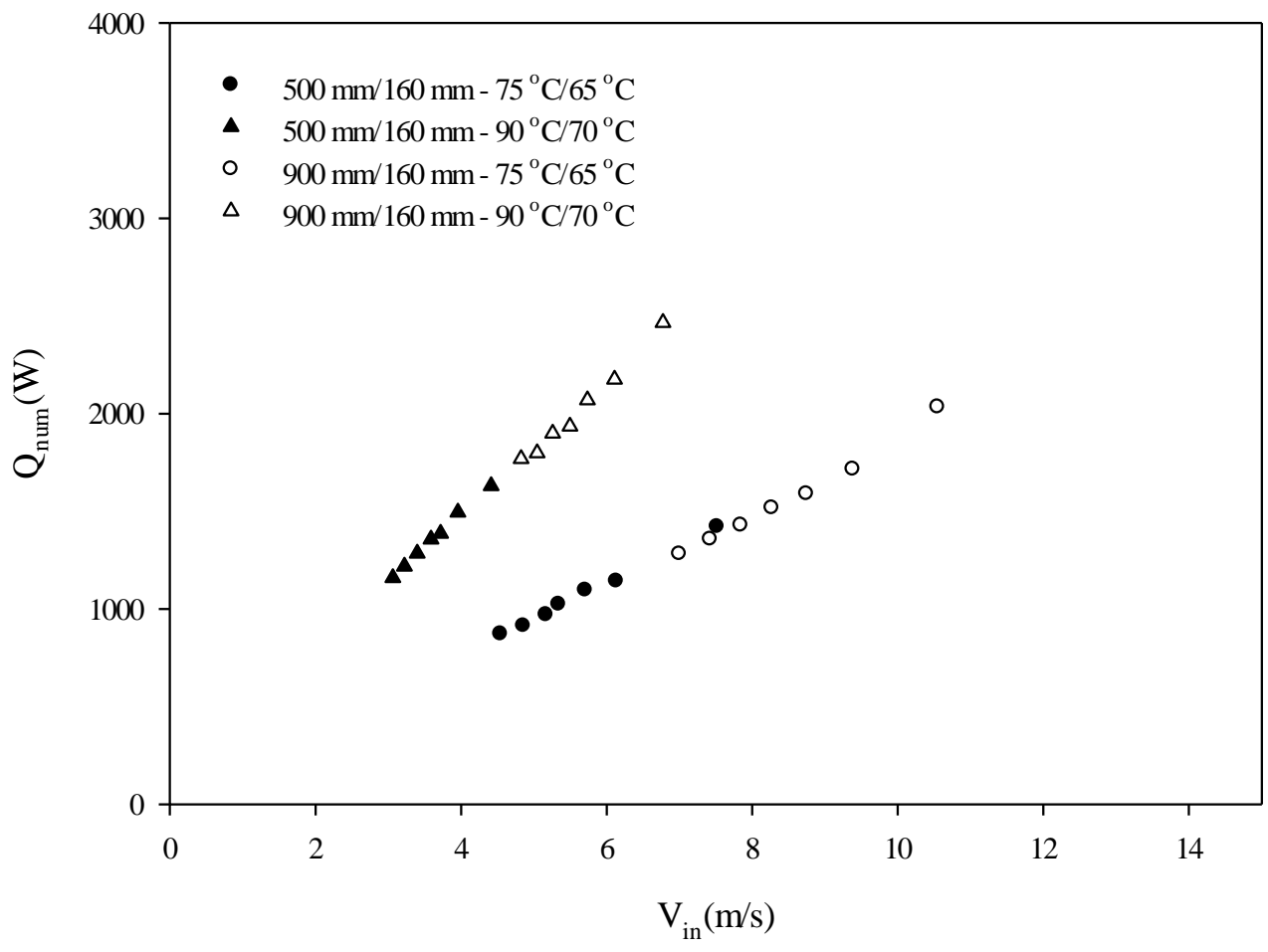

(a) 
Journal of Thermal Engineering, Research Article, Vol. 5, No. 4, pp. 251-270, July, 2019

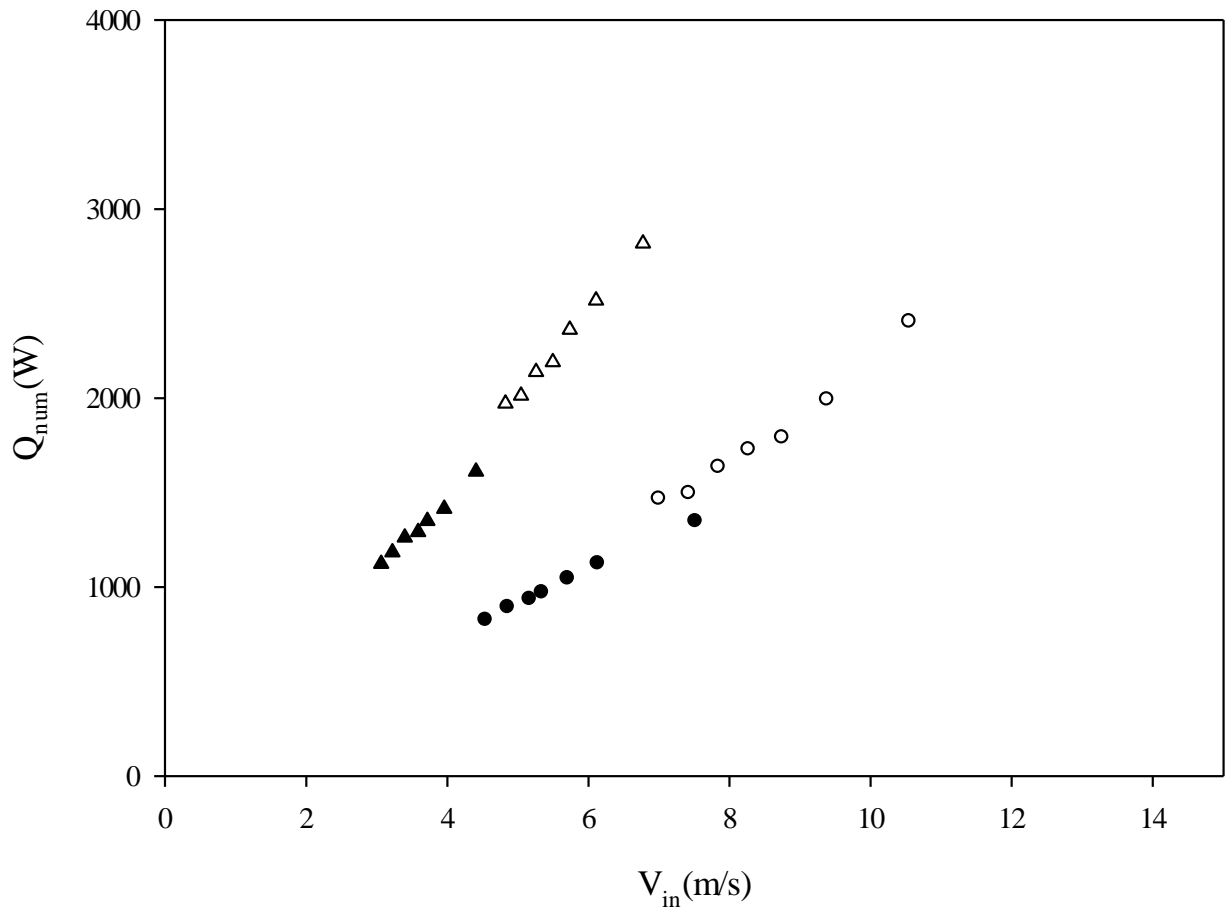

(b)

Figure 3. The variation of total heat transfer rate values with inlet water velocity (a) for cornered end, (b) for chamfered end radiators

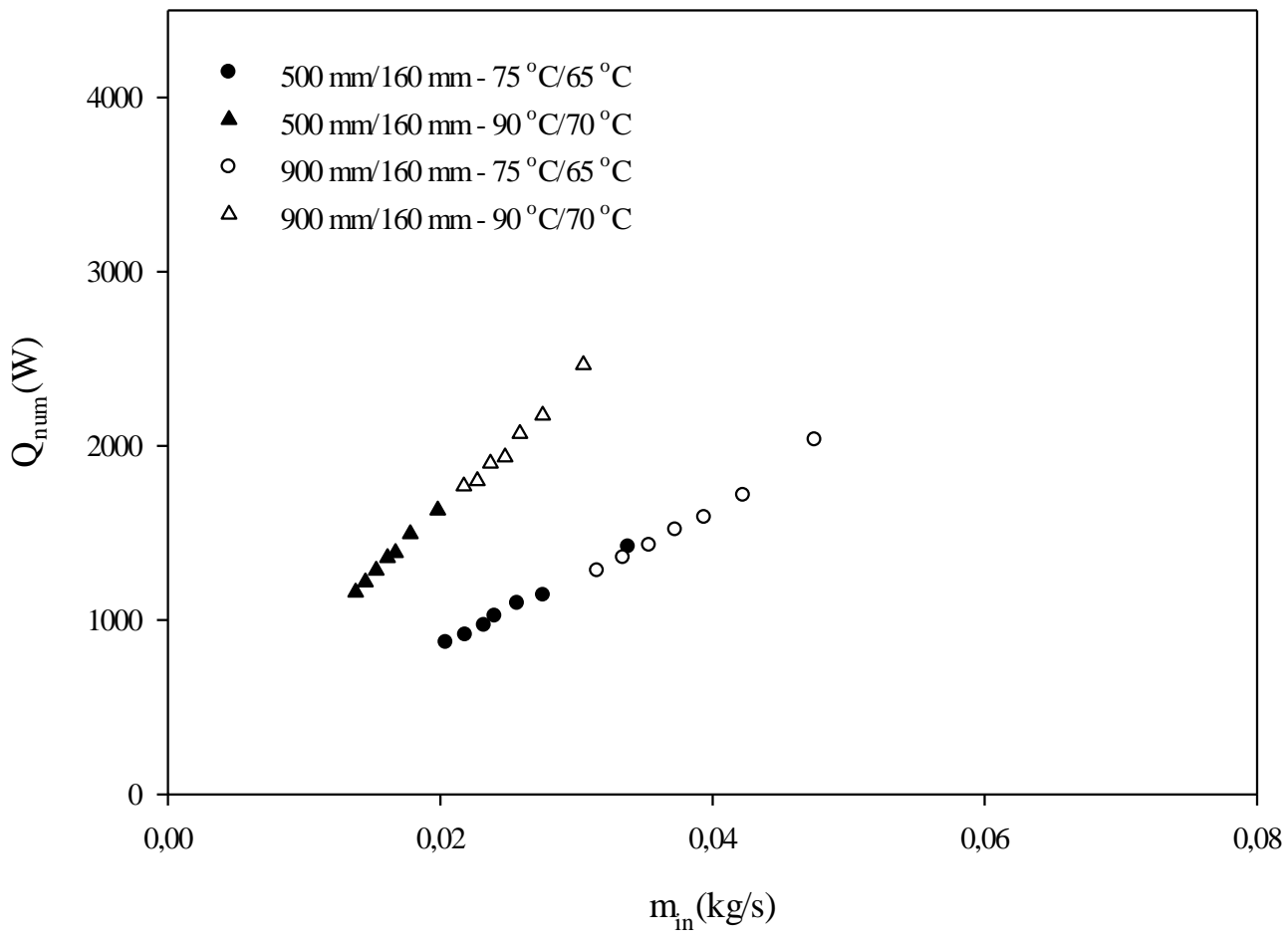

(a) 
Journal of Thermal Engineering, Research Article, Vol. 5, No. 4, pp. 251-270, July, 2019

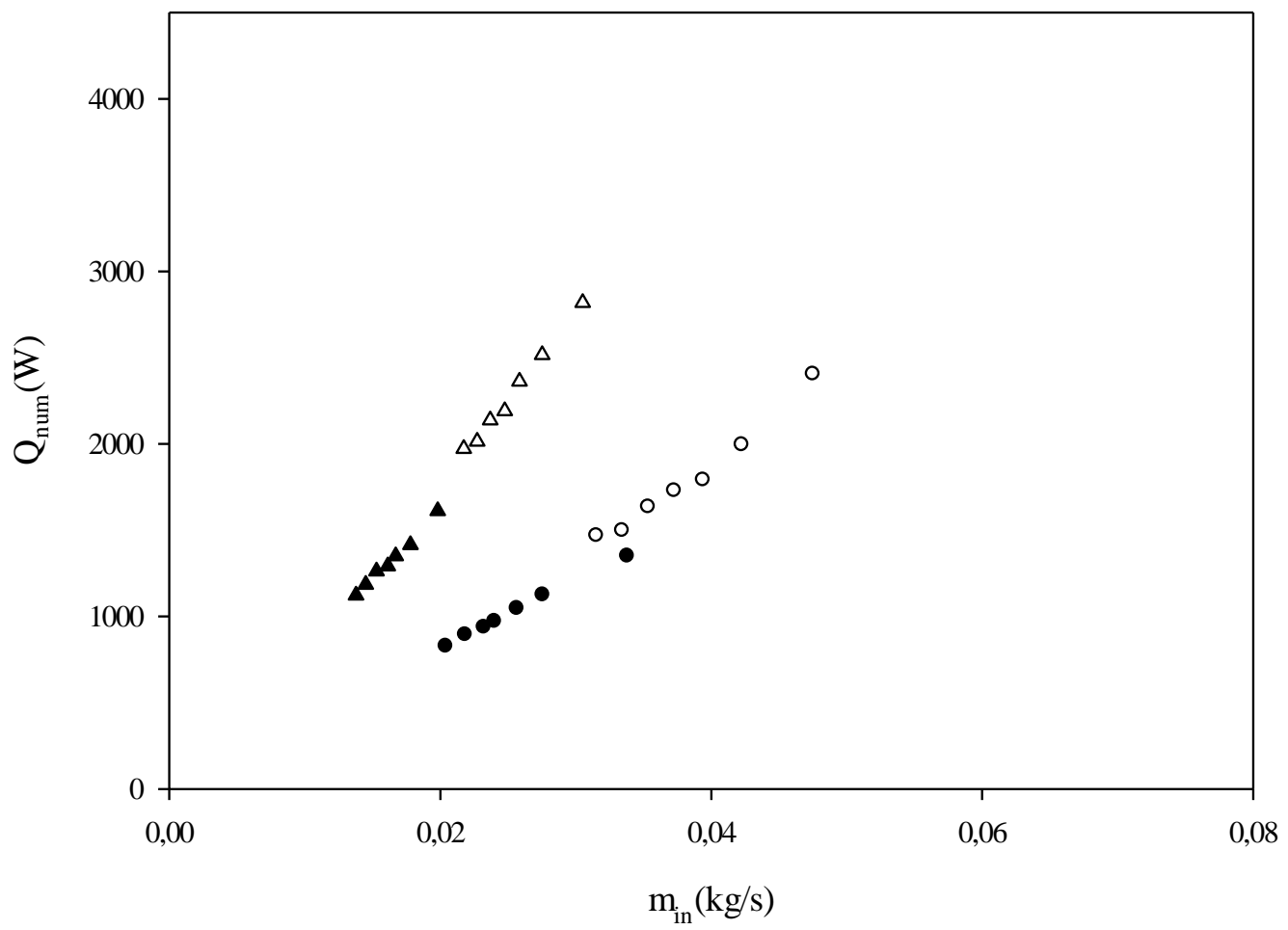

(b)

Figure 4. The change of total heat transfer rate found via ANSYS with mass flow inlet (a) for cornered end, (b) for chamfered end radiators

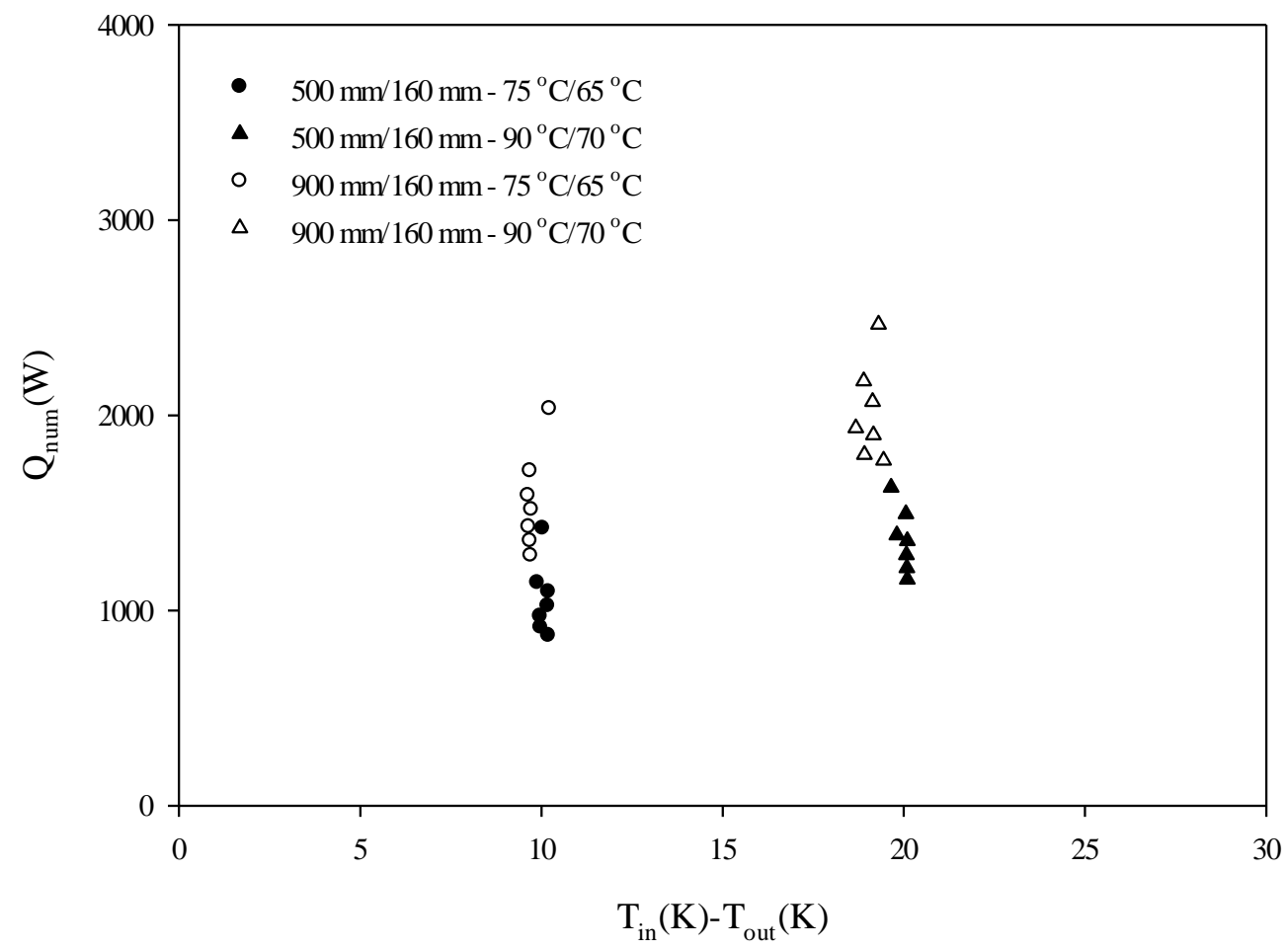

(a) 
Journal of Thermal Engineering, Research Article, Vol. 5, No. 4, pp. 251-270, July, 2019

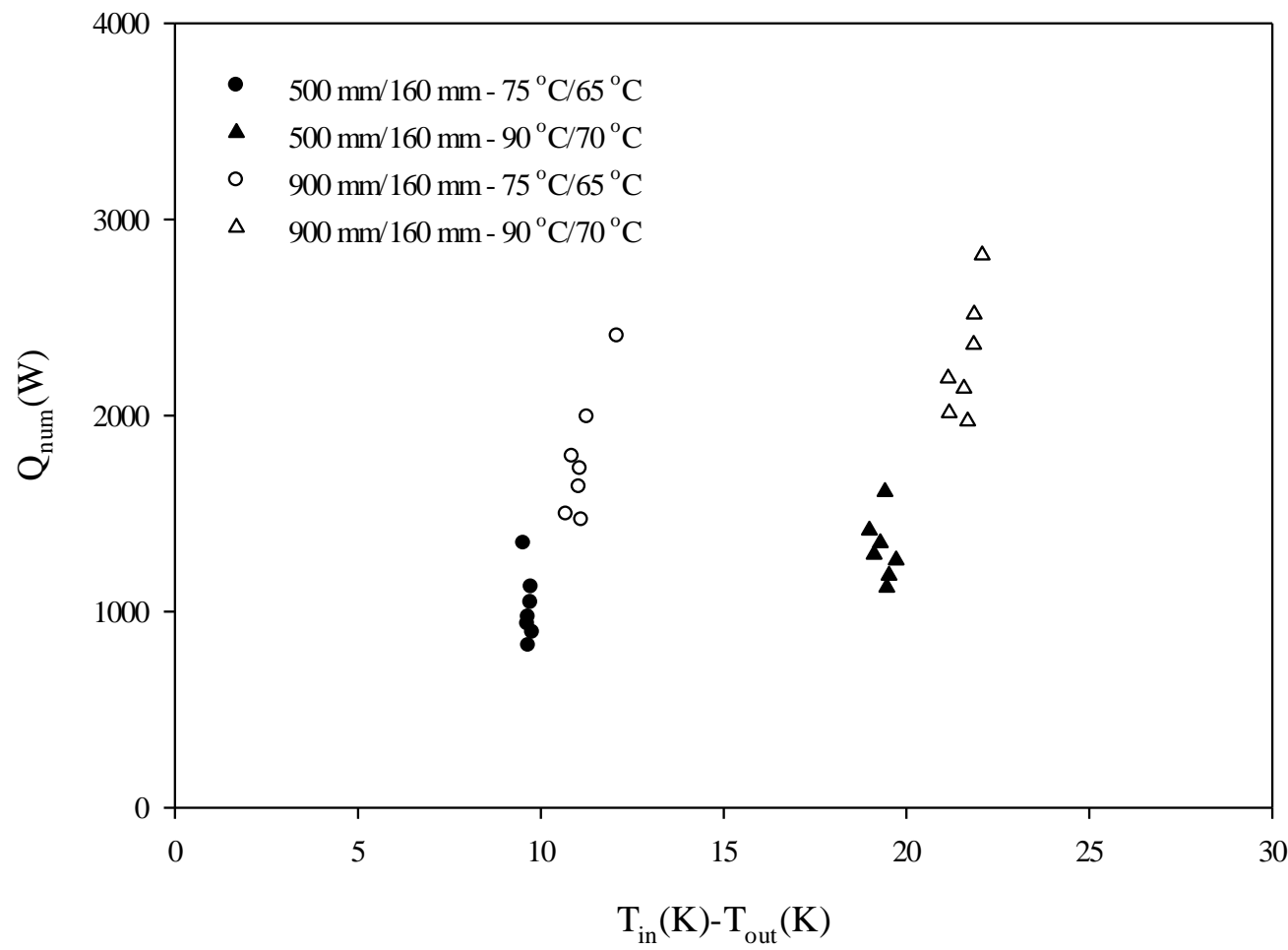

(b)

Figure 5. The alteration of total heat transfer rate obtained via ANSYS with radiator inlet and outlet temperature difference (a) for cornered end, (b) for chamfered end radiators

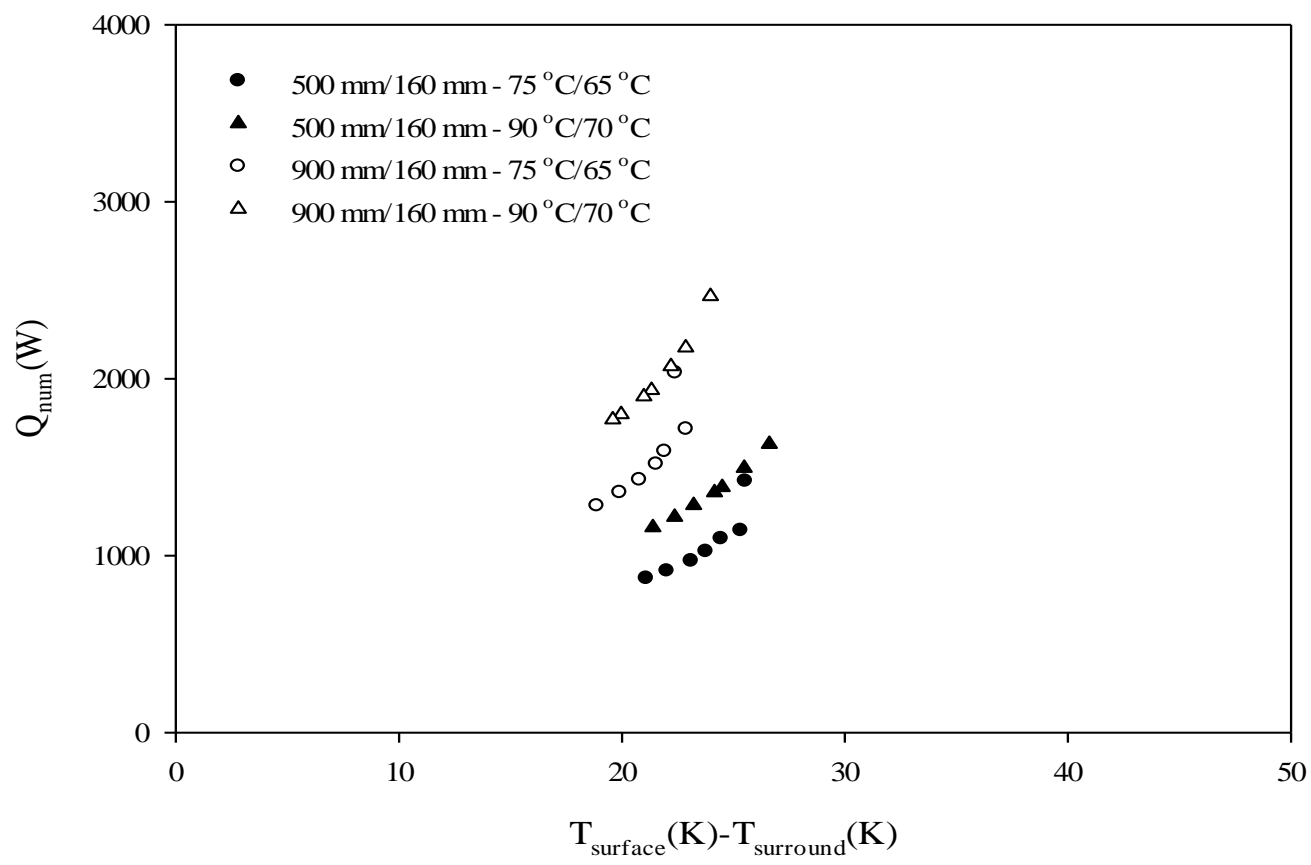

(a) 
Journal of Thermal Engineering, Research Article, Vol. 5, No. 4, pp. 251-270, July, 2019

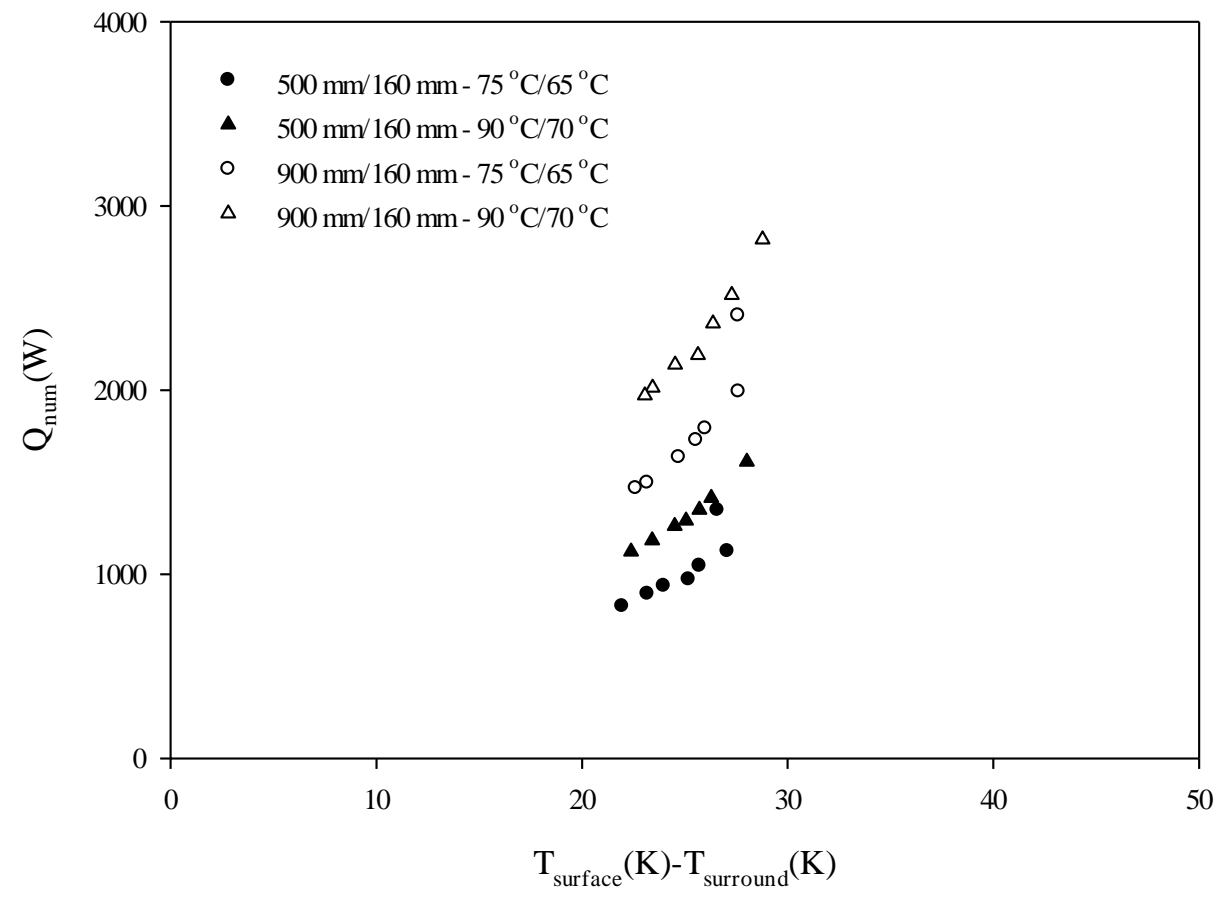

(b)

Figure 6. The variation of total heat transfer rate obtained via ANSYS as the temperature difference between radiator surface and air varies, (a) for cornered end, (b) for chamfered end radiators

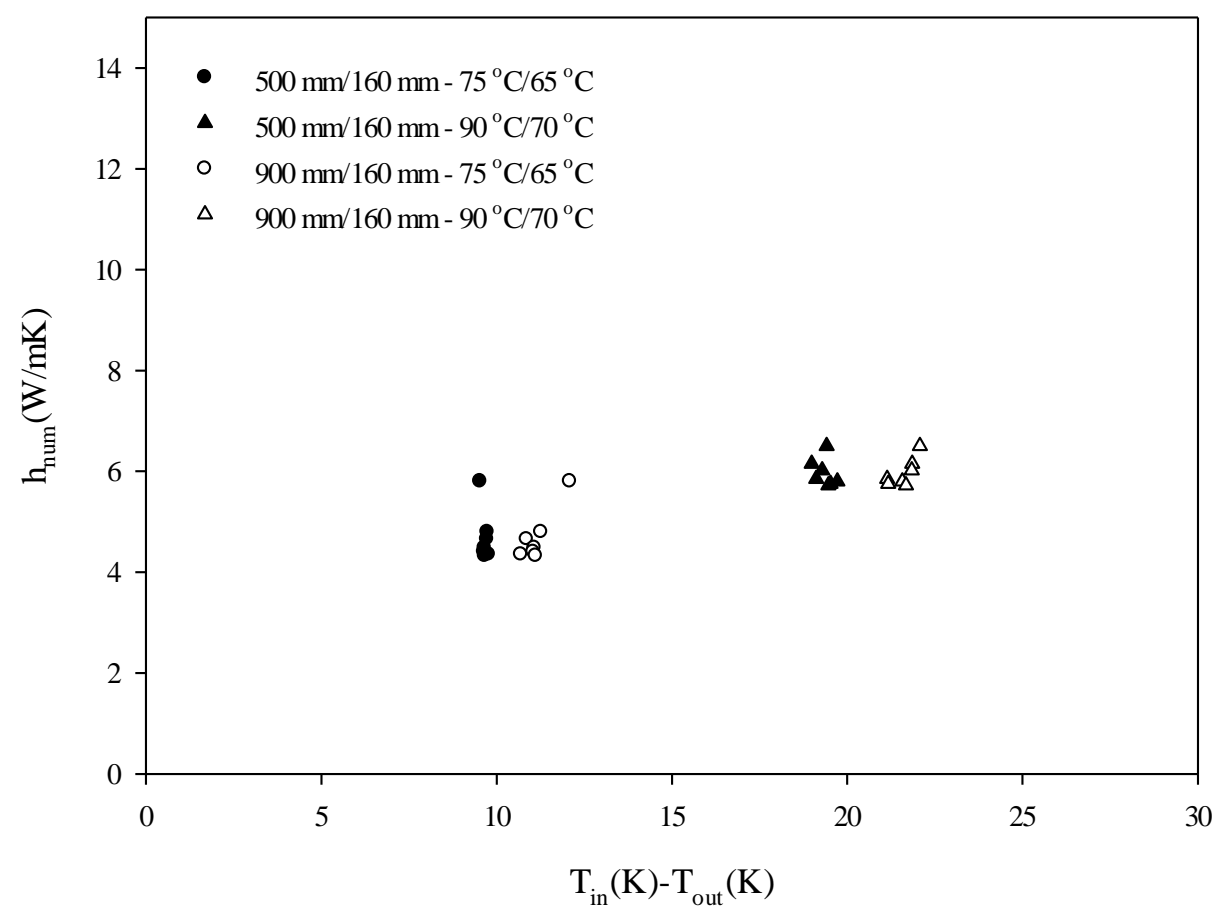

(a) 
Journal of Thermal Engineering, Research Article, Vol. 5, No. 4, pp. 251-270, July, 2019

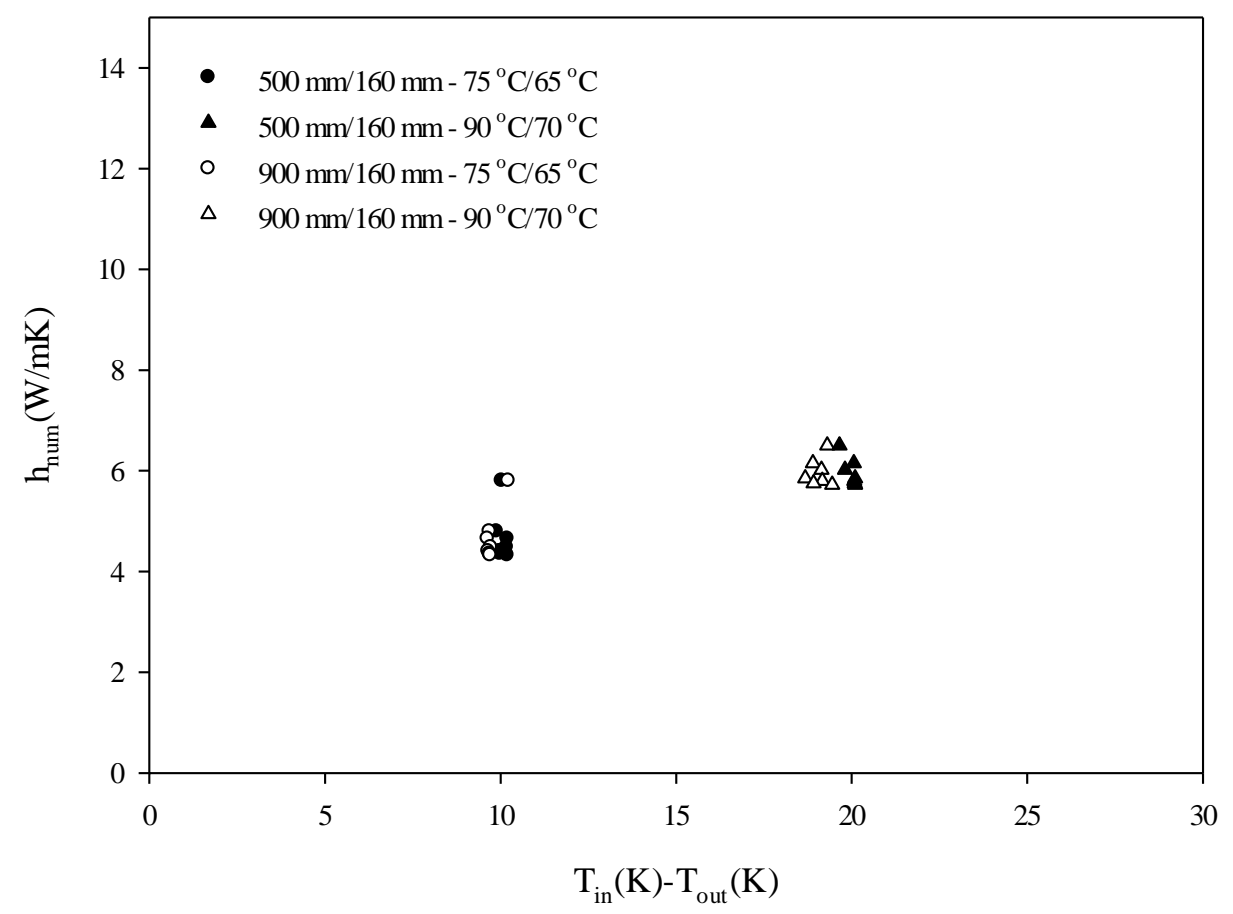

(b)

Figure 7. The change of convective heat transfer coefficient occurring over the radiator, with the variation of the temperature difference between radiator inlet and outlet temperatures,

(a) for cornered end, (b) for chamfered end radiators

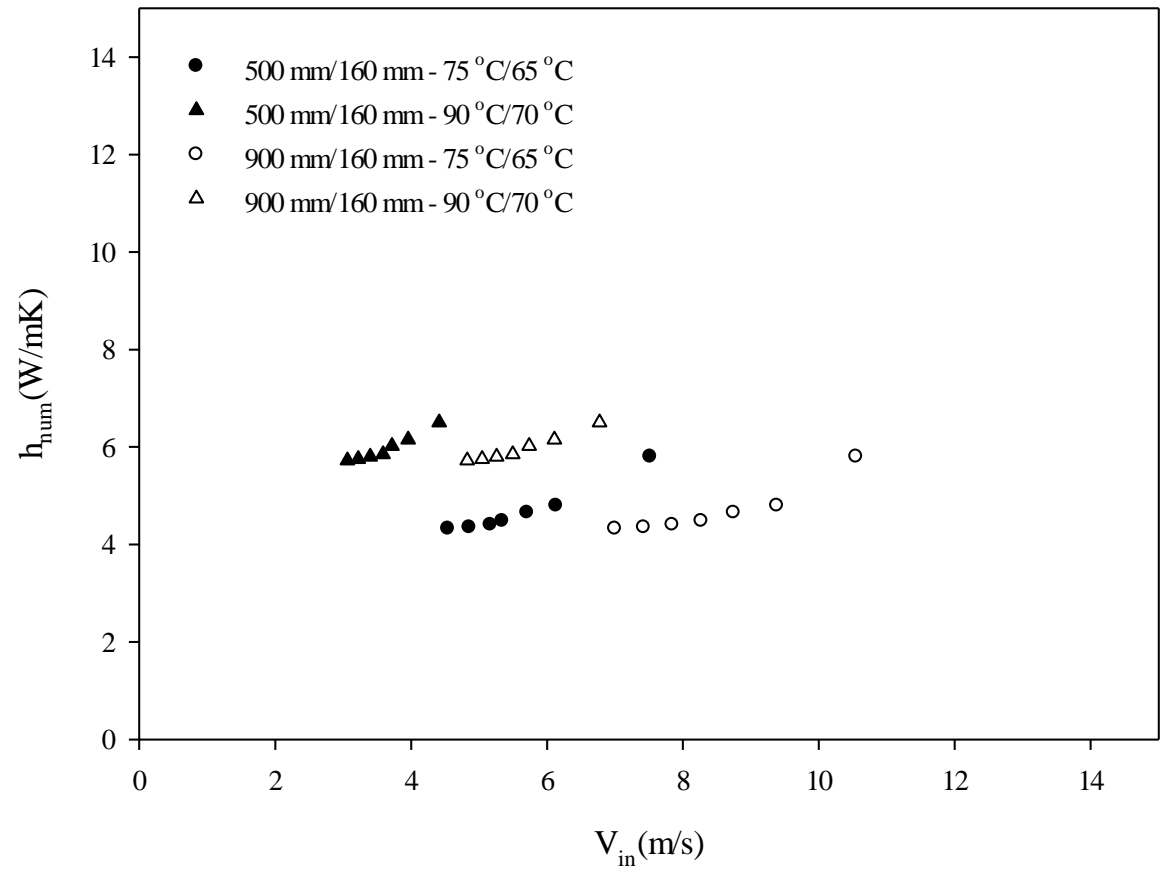

(a) 
Journal of Thermal Engineering, Research Article, Vol. 5, No. 4, pp. 251-270, July, 2019

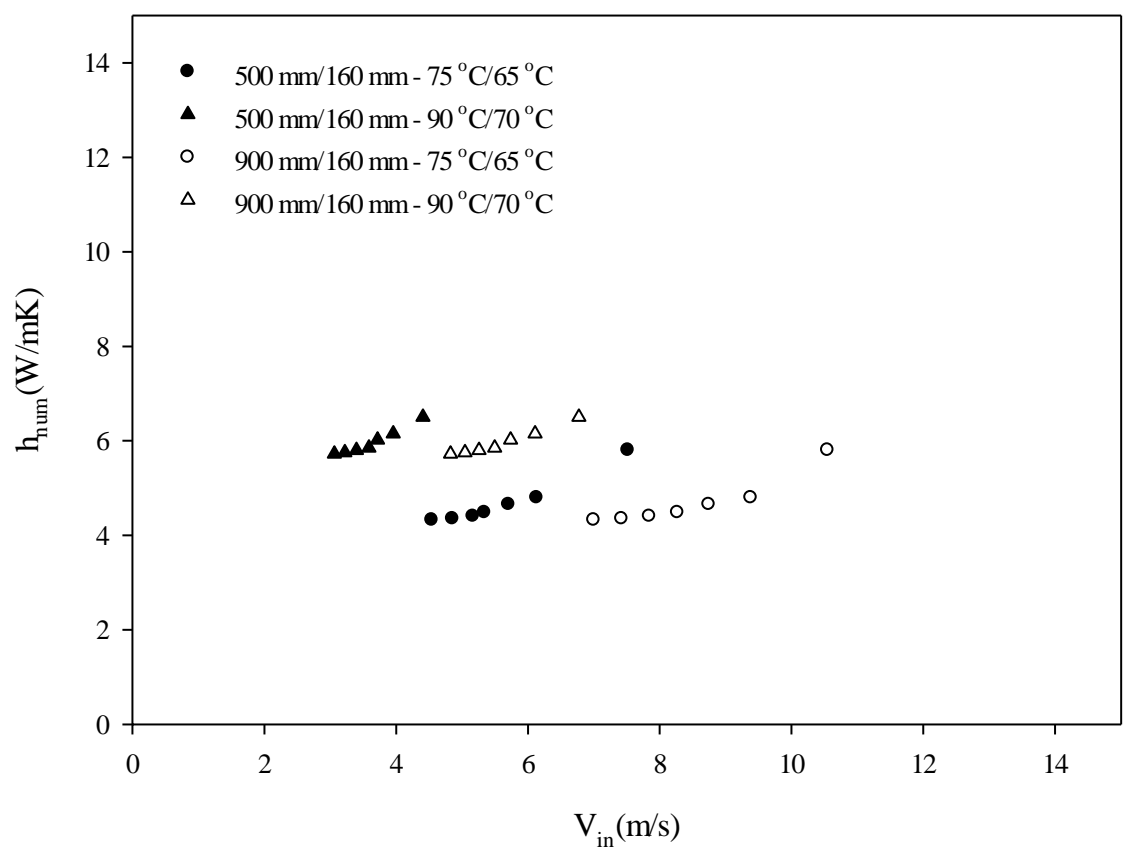

(b)

Figure 8. The variation of convective heat transfer coefficient values with inlet water velocity (a) for cornered end, (b) for chamfered end radiators

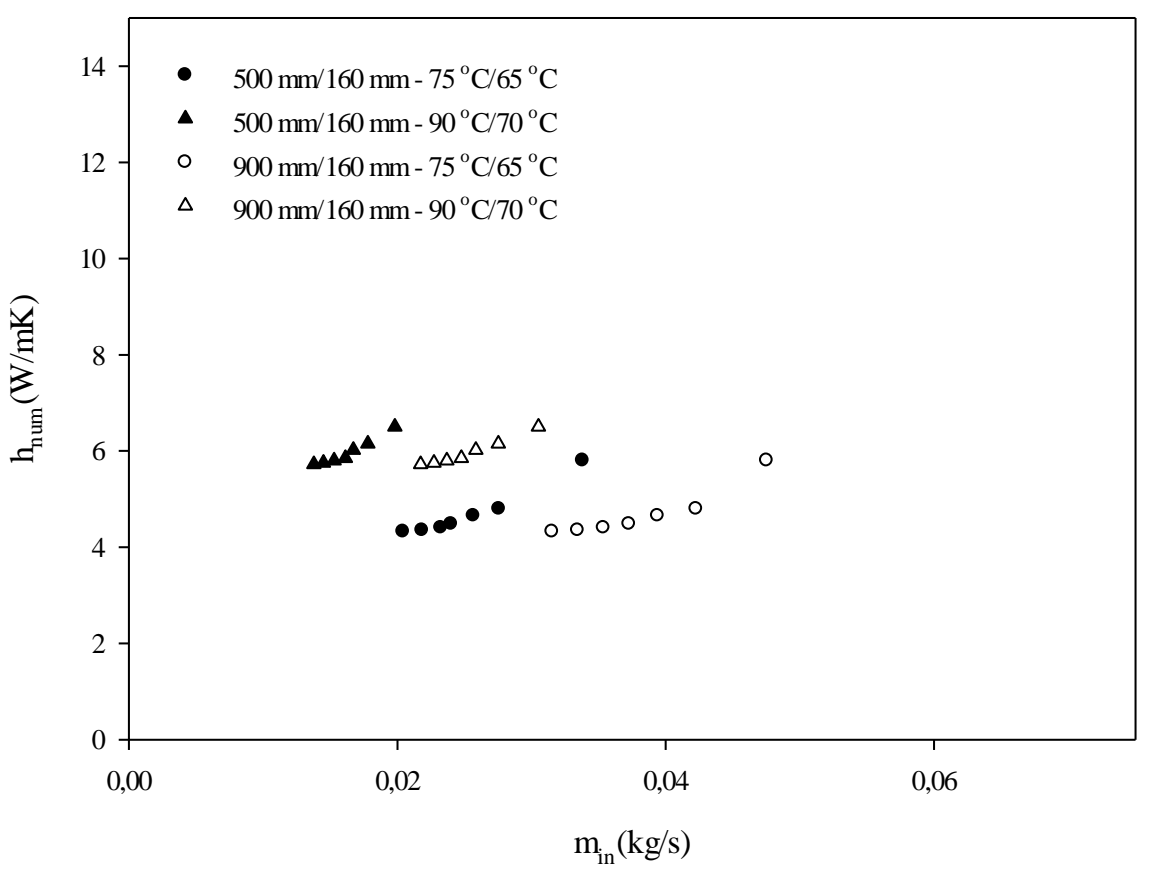

(a) 
Journal of Thermal Engineering, Research Article, Vol. 5, No. 4, pp. 251-270, July, 2019

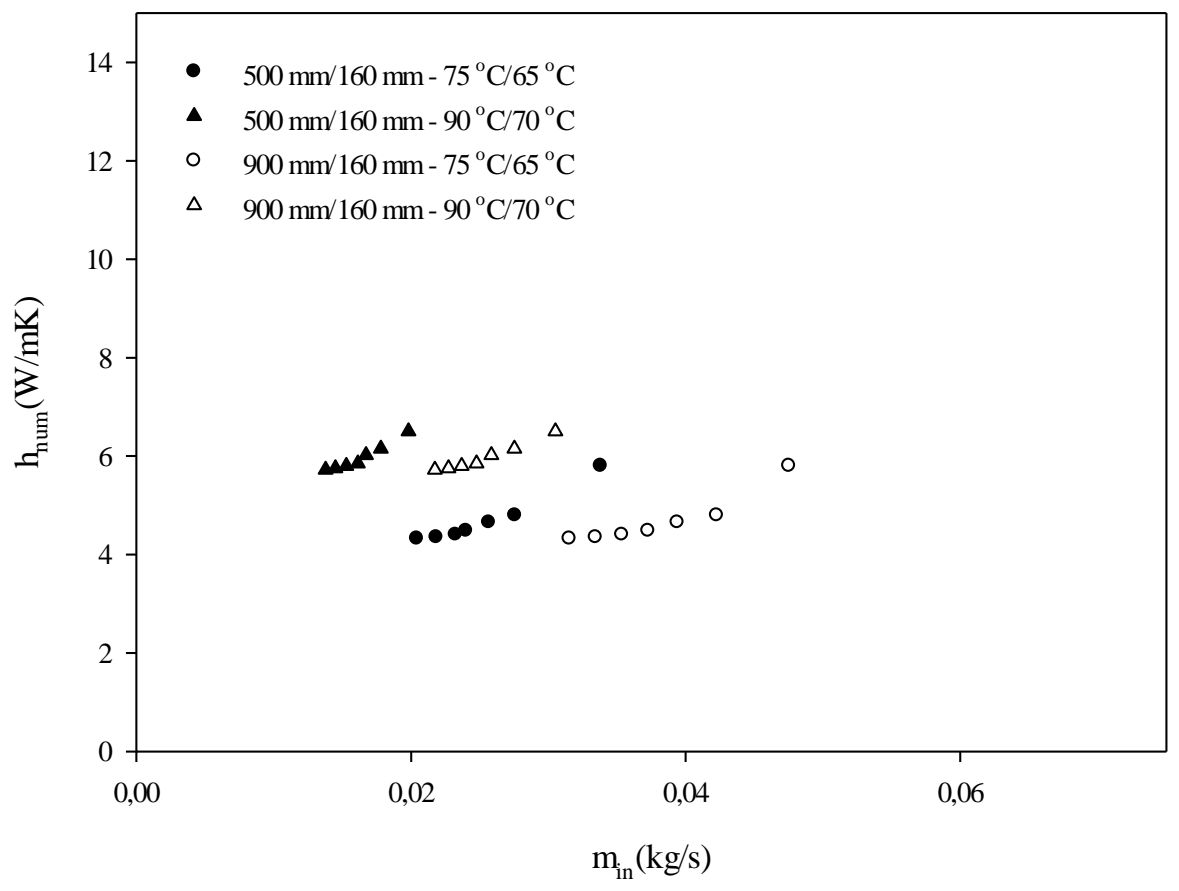

(b)

Figure 9. The change of convective heat transfer coefficient with mass flow inlet (a) for cornered end,

(b) for chamfered end radiators

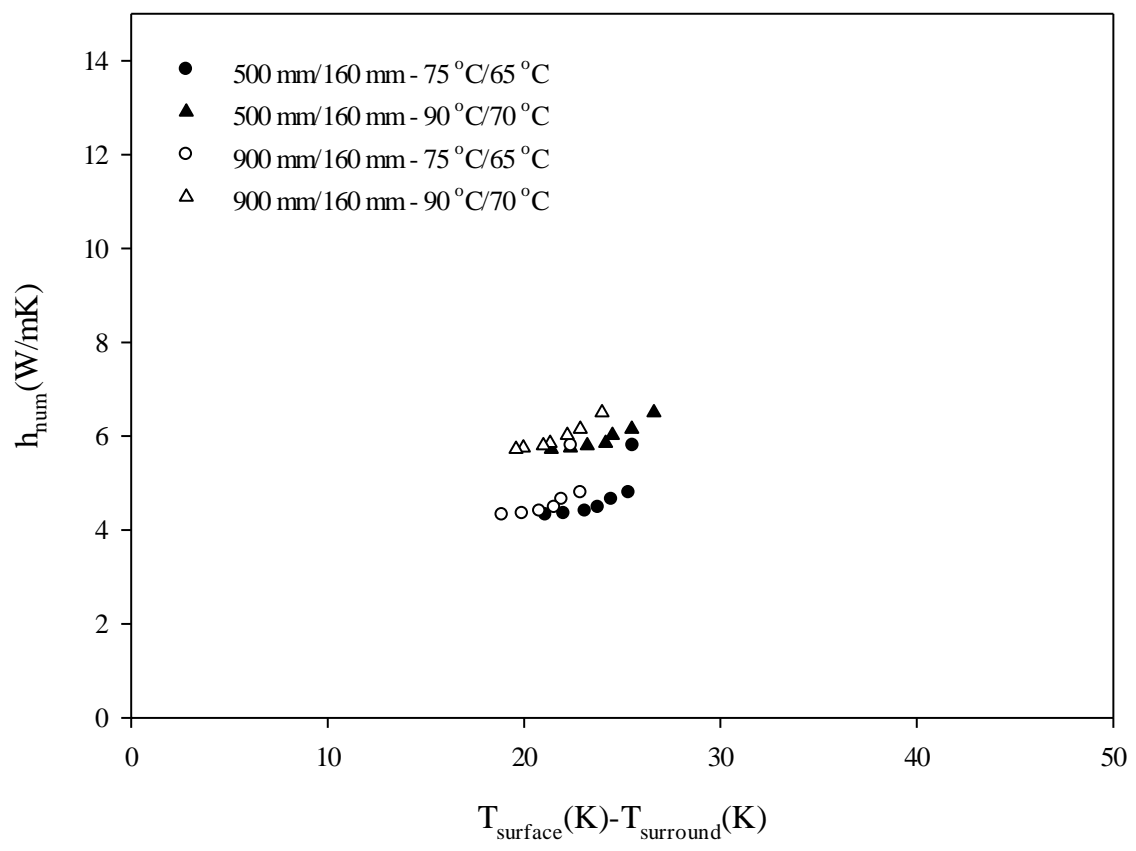

(a) 
Journal of Thermal Engineering, Research Article, Vol. 5, No. 4, pp. 251-270, July, 2019

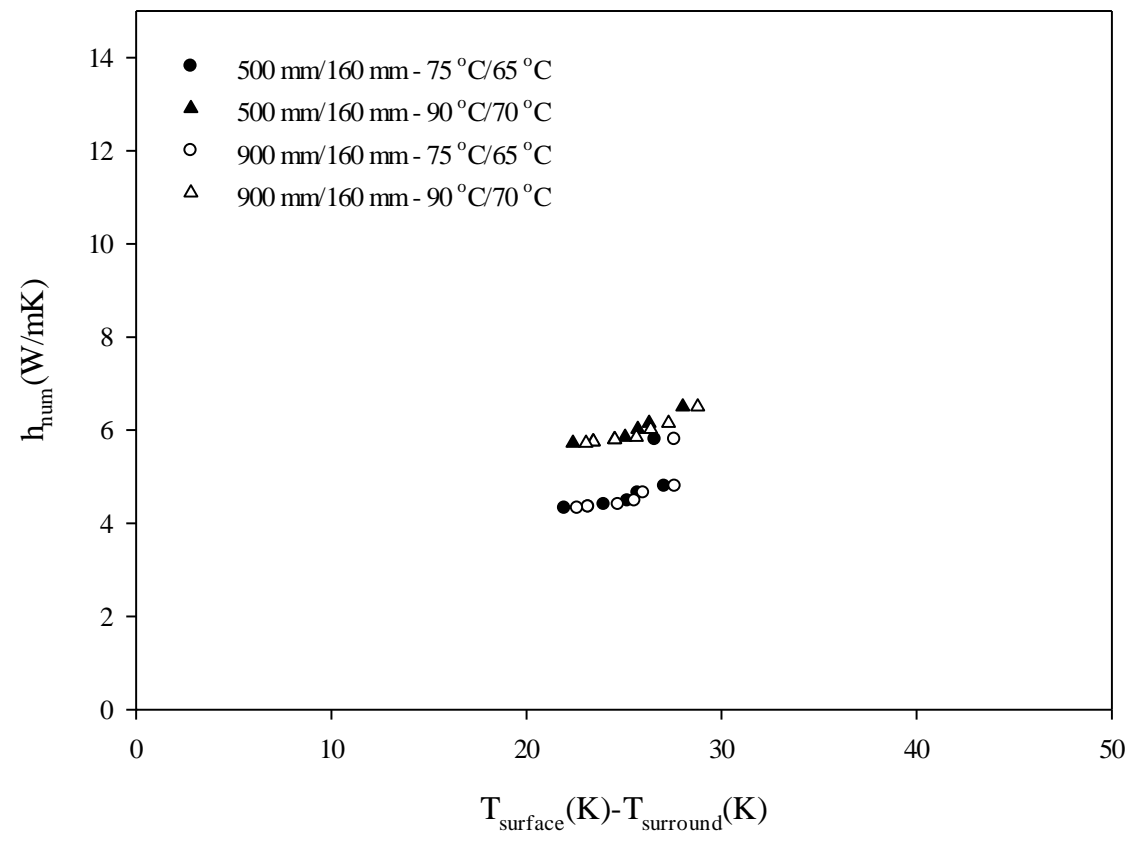

(b)

Figure 10. The variation of convective heat transfer coefficient obtained via ANSYS as the temperature difference between radiator surface and air changes, (a) for cornered end, (b) for chamfered end radiators

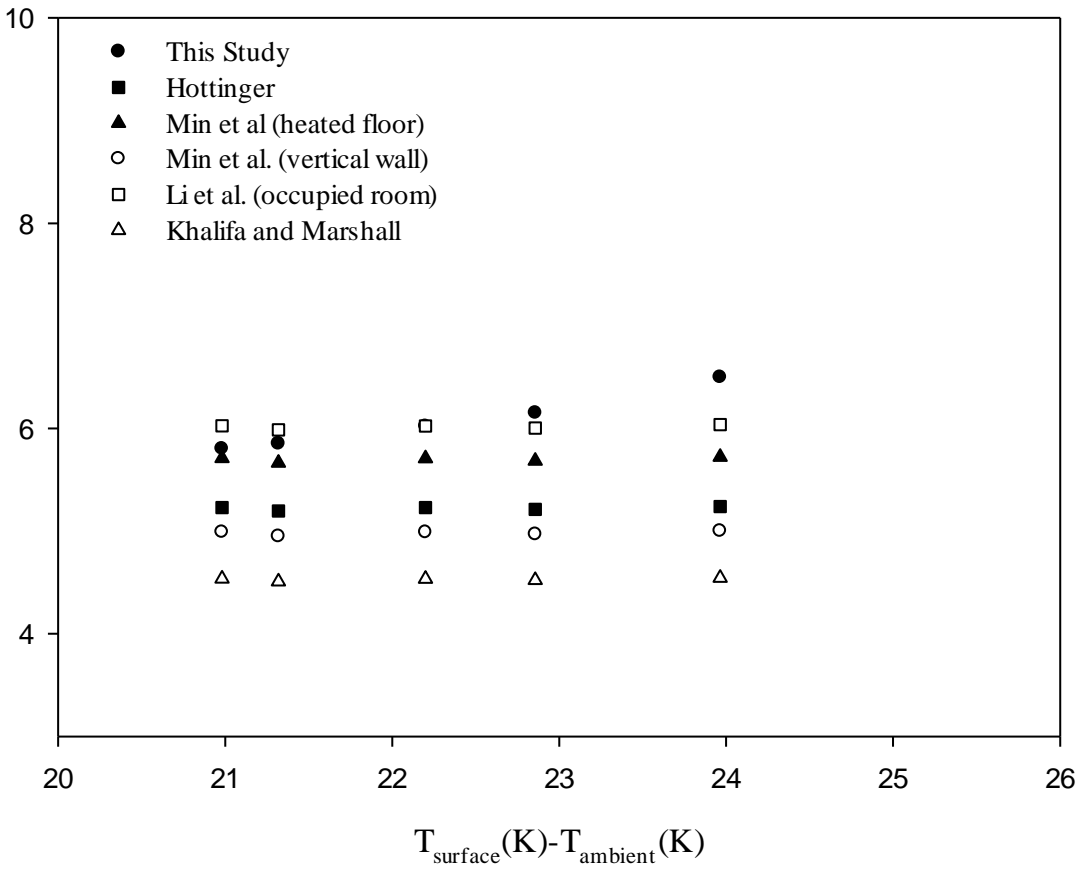

(a) 


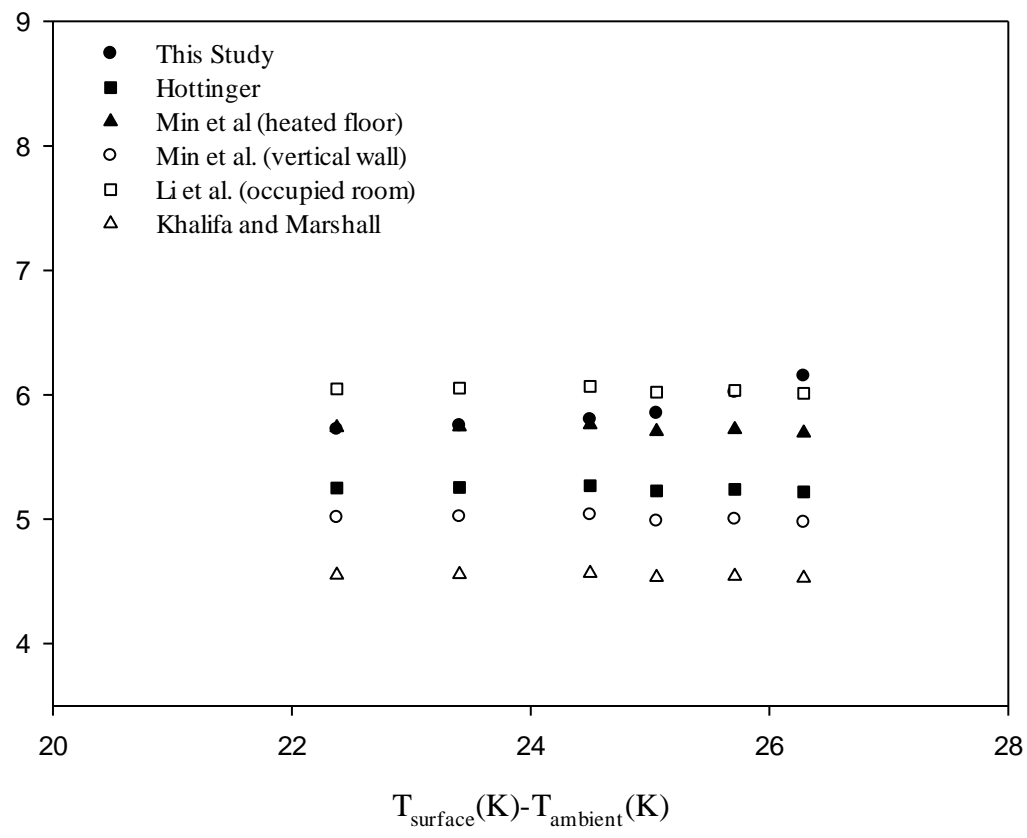

(b)

Figure 11. Comparison between the results of this study and the results obtained using the correlations derived by other researchers, (a) for a cornered end $900 \mathrm{~mm} / 160 \mathrm{~mm} 90^{\circ} \mathrm{C} / 70^{\circ} \mathrm{C}$ radiator,

(b) for a chamfered end $500 \mathrm{~mm} / 160 \mathrm{~mm} 90^{\circ} \mathrm{C} / 70^{\circ} \mathrm{C}$

Table 3. Some of the operating conditions and findings of $900 \mathrm{~mm}-160 \mathrm{~mm}$ radiator for $90{ }^{\circ} \mathrm{C} / 70{ }^{\circ} \mathrm{C}$

\begin{tabular}{|c|c|c|c|c|c|c|c|c|}
\hline \multicolumn{7}{|c|}{$(900 \mathrm{~mm}-160 \mathrm{~mm})\left(90^{\circ} \mathrm{C} / 70{ }^{\circ} \mathrm{C}\right)$ Cornered End Radiator } \\
\hline $\mathrm{W} / \mathrm{m}^{2} \mathrm{~K}$ & $\mathrm{~m} / \mathrm{s}$ & $\mathrm{K}$ & $\mathrm{K}$ & Watt & Watt & $\%$ & $\mathrm{~K}$ & $\mathrm{~K}$ \\
\hline $\mathrm{h}$ & $\mathrm{v}_{\text {in }}$ & $\mathrm{T}_{\text {in }}$ & $\mathrm{T}_{\text {out }}$ & $\mathrm{Q}_{\text {num }}$ & $\mathrm{Q}_{\text {exp }}$ & $\begin{array}{c}\text { Error } \\
\text { rate }\end{array}$ & $\mathrm{T}_{\text {surface }}$ & $\mathrm{T}_{\text {ambient }}$ \\
\hline 6,5 & 6,77 & 363 & 343,69 & 2465,76 & 2550 & 3,30 & 306.96 & 283 \\
\hline 6,15 & 6,10 & 363 & 344,10 & 2176,20 & 2300 & 5,38 & 310.86 & 288 \\
\hline 6,02 & 5,73 & 363 & 343,86 & 2070,41 & 2160 & 4,14 & 313.20 & 291 \\
\hline 5,85 & 5,49 & 363 & 344,32 & 1935,40 & 2070 & 6,50 & 314.32 & 293 \\
\hline 5,8 & 5,25 & 363 & 343,83 & 1899,97 & 1980 & 4,04 & 315.98 & 295 \\
\hline 5,75 & 5,04 & 363 & 344,08 & 1799,20 & 1900 & 5,30 & 316.96 & 297 \\
\hline 5,72 & 4,82 & 363 & 343,55 & 1768,67 & 1800 & 1,74 & 318.59 & 299 \\
\hline
\end{tabular}


Journal of Thermal Engineering, Research Article, Vol. 5, No. 4, pp. 251-270, July, 2019

Table 4. Some of the operating conditions and findings of $500 \mathrm{~mm}-160 \mathrm{~mm}$ radiator for $90{ }^{\circ} \mathrm{C} / 70{ }^{\circ} \mathrm{C}$

\begin{tabular}{|c|c|c|c|c|c|c|c|c|}
\hline \multicolumn{7}{|c|}{$(500 \mathrm{~mm}-160 \mathrm{~mm})\left(90^{\circ} \mathrm{C} / 70^{\circ} \mathrm{C}\right)$ Cornered End Radiator } \\
\hline $\mathrm{W} / \mathrm{m}^{2} \mathrm{~K}$ & $\mathrm{~m} / \mathrm{s}$ & $\mathrm{K}$ & $\mathrm{K}$ & Watt & Watt & $\%$ & $\mathrm{~K}$ & $\mathrm{~K}$ \\
\hline $\mathrm{h}$ & $\mathrm{V}_{\text {in }}$ & $\mathrm{T}_{\text {in }}$ & $\mathrm{T}_{\text {out }}$ & $\mathrm{Q}_{\text {num }}$ & $\mathrm{Q}_{\text {exp }}$ & $\begin{array}{c}\text { Error } \\
\text { rate }\end{array}$ & $\mathrm{T}_{\text {surface }}$ & $\mathrm{T}_{\text {ambient }}$ \\
\hline 6.5 & 4.41 & 363 & 343.35 & 1629.942 & 1660 & 1.81 & 309.617 & 283 \\
\hline 6.15 & 3.95 & 363 & 342.937 & 1494.397 & 1490 & -0.29 & 313.485 & 288 \\
\hline 6.02 & 3.71 & 363 & 343.191 & 1385.869 & 1400 & 1 & 315.492 & 291 \\
\hline 5.85 & 3.58 & 363 & 342.901 & 1356.829 & 1350 & -0.5 & 317.144 & 293 \\
\hline 5.8 & 3.39 & 363 & 342.929 & 1284.305 & 1280 & -0.33 & 318.215 & 295 \\
\hline 5.75 & 3.22 & 363 & 342.918 & 1218.02 & 1220 & 0.16 & 319.357 & 297 \\
\hline 5.72 & 3.06 & 363 & 342.902 & 1159.013 & 1160 & 0.08 & 320.38 & 299 \\
\hline
\end{tabular}

\section{RESULTS AND DISCUSSION}

The main purposes of this study are to numerically find heat transfer characteristics occurring over the household iron casting radiators produced by a company, and to compare the obtained numerical results with experimental results of the producer in terms of heat transfer rates, and also compare the numerically calculated convective heat transfer coefficient values with the results found by executing the correlations derived by researchers cited in Tables 1 and 2.

Figures $2 \mathrm{a}$ and $2 \mathrm{~b}$ illustrate the comparison between the experimental data and the numerically obtained values with this study. At different radiator dimensions, as well as, inlet and outlet temperatures, it is observed that numerically acquired data predicts the experimental results of the radiator company within 5\% and 10\% deviation ratios for cornered end and chamfered end radiators, respectively. This comparison proves the correctness of the computational model performed in the present study.

Figures $3 \mathrm{a}$ and $3 \mathrm{~b}$ demonstrate the increase in heat transfer rate through the radiators at different radiator sizes and water inlet and outlet temperatures, and at cornered end and chamfered end radiators, respectively. As expected, the more water velocities in radiators result in the rise in forced convection and thus heat transfer rate ascends. It is also obvious that the increase on radiator dimensions has led to a sharp increase in heat transfer rate. Very similarly, as shown in Figures $4 \mathrm{a}$ and $4 \mathrm{~b}$ the increase in mass flow rate flowing in radiators at different dimensions and inlet/outlet temperatures accounts for the augmentation on radiator's heat transfer rate.

Figures $5 \mathrm{a}$ and $5 \mathrm{~b}$ reveal that at the same radiator inlet and outlet water temperatures, as the radiator dimension rises from $500 \mathrm{~mm}$ to $900 \mathrm{~mm}$, the heat transfer rate of the radiator shows a notable increase, for cornered end and chamfered end radiators, respectively. Moreover, it is evident that at the same radiator dimensions, with ascending values of water inlet temperatures, the heat transfer rate values illustrate a remarkable advance. Additionally, the data illustrated in Figures $6 \mathrm{a}$ and $6 \mathrm{~b}$ demonstrate the augmentation in heat transfer rate of radiators with increasing values of temperature difference between surface and surrounding air temperature, at cornered end and chamfered end radiators, respectively.

Figures $7 \mathrm{a}$ and $7 \mathrm{~b}$ shows the convective heat transfer characteristics occurring over the radiators and their variation with inlet and outlet temperature difference values. It can be observed that at different radiator dimensions $(500 \mathrm{~mm}$ and $900 \mathrm{~mm}$ ) and at the same radiator inlet and outlet temperatures, the convective heat transfer coefficient draws very slight variations, whereas, it shows a more remarkable change as the abovementioned temperature difference rises, when dimensions are the same. 

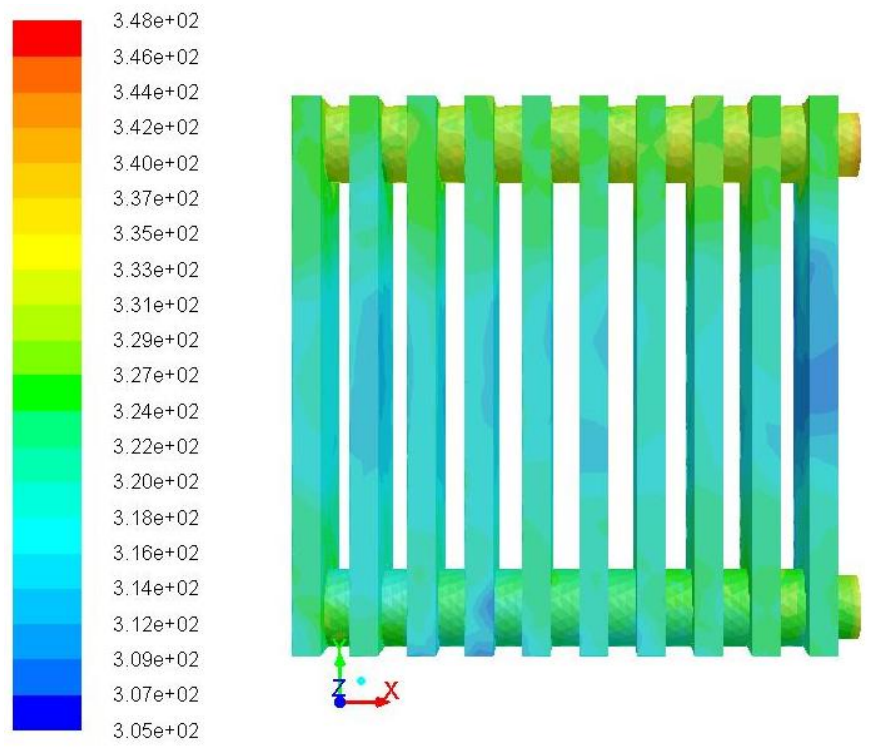

Figure 12. Temperature distribution on the surface of $500 \mathrm{~mm}-160 \mathrm{~mm}$ radiator in $26{ }^{\circ} \mathrm{C}$ ambient temperature

Figures $8 \mathrm{a}$ and $8 \mathrm{~b}$ illustrate the alteration of convective heat transfer coefficients over radiator surfaces with water velocity inlet values to the radiator. Similar to the Figures $3 a$ and $3 b$ demonstrating the change of heat transfer rate with velocity inlet values, the convective heat transfer coefficient values also rise with increasing velocity inlet values, since higher values of velocity have induced forced convection at higher levels within the radiator and therefore causing higher values of convective heat transfer coefficients over the radiator. In a very similar trend, Figures $9 \mathrm{a}$ and $9 \mathrm{~b}$ draw the variation of the convective heat transfer coefficient with changing values of mass flow rates in radiators, for cornered end and chamfered end radiators, respectively. It is clear that with an increase in mass flow rate, in all case studies, the convective heat transfer coefficient demonstrates a noticeable growth over the radiator surface.

In Figures 10a and 10b show the change in convective heat transfer coefficient with the temperature difference between surface and surrounding air temperatures. From the figures, it can be seen that as the aforementioned temperature difference grows, due to increasing air movements over the radiator, the convective heat transfer coefficient ascends. Also, as expected, this coefficient illustrate a clear increase as the radiator water inlet temperature rises from $90^{\circ} \mathrm{C}$ to $75^{\circ} \mathrm{C}$. Moreover, it should be noted that a very slight increase on this coefficient could be observed while one dimension of the radiators descends from $900 \mathrm{~mm}$ to $500 \mathrm{~mm}$.

In addition to the validations implemented with experimental data in Figures $2 \mathrm{a}$ and $2 \mathrm{~b}$, the results obtained through the present work were compared with the data found utilizing correlations explored by some other researchers in the literature. In Figures 11a and 11b, for a $900 \mathrm{~mm} / 160 \mathrm{~mm}$ cornered end, and for a chamfered end $500 \mathrm{~mm} / 160 \mathrm{~mm}$ radiator, respectively, this comparison has been made. It is evident through the figures that the results of the present study lie within the range of the data acquired by executing the correlations cited in these figures. It should be noted that the sole successful correlation predicting the results of the current study which has been derived for free plates, is Hottinger's correlation, with an average deviation ratio of $4.08 \%$. On the other hand, the correlations explored for enclosures have enabled much more consistent outputs with the results of this study. While the correlations proposed for heated floor and vertical walls by Min et al. deviate by $0.72 \%$ and $12.55 \%$ at average, respectively; the correlation of $\mathrm{Li}$ et al. obtained for an occupied office room under normal working conditions, deviates at an average value of $10.5 \%$. 
Figure 12 illustrates an image via Ansys, displaying the temperature distribution in one of the tested radiators which was abovementioned and presented in Figure 1. The influence of heat loss from hot water to surrounding air is noticed through this figure obviously.

\section{CONCLUSION}

As well as the thermal capacities of household radiators, convective heat transfer coefficient values occurring over their surfaces comprise the most crucial issues in terms of energy economy and thermal comfort. From this point of view, in the present study, a numerical model investigating household radiators at different dimensions, water inlet temperatures, inlet velocities and geometric shapes was generated by means of the program Ansys 17 .

To obtain a The radiators were simulated using wide range of input ambient temperature conditions from 10 ${ }^{\circ} \mathrm{C}$ to $26{ }^{\circ} \mathrm{C}$ and water velocity ranging from $3.06 \mathrm{~m} / \mathrm{s}$ to $7.51 \mathrm{~m} / \mathrm{s}$ for $500 \mathrm{~mm} / 160 \mathrm{~mm}$ type radiator and $4.82 \mathrm{~m} / \mathrm{s}$ to $10.54 \mathrm{~m} / \mathrm{s}$ for $900 \mathrm{~mm} / 160 \mathrm{~mm}$ type radiator. The deductions obtained were summed up as follows:

The heat transfer capacity and the convective heat transfer coefficient over the radiator increase with increasing values of water inlet velocity and also mass flow rate, due to growing values of forced convection within radiators.

Using a producer's catalogue, found thermal capacity values and also the model developed at different dimensions, geometric shapes and water inlet temperatures, have been validated within the deviation values of $5 \%$, and $10 \%$, for cornered end, and chamfered end radiator types, respectively.

The results regarding the convective heat transfer coefficient values were compared with the data obtained using the correlations found by some other researchers, and noticed that a favorable consistency has been achieved.

\section{ACKNOWLEDGMENTS}

The authors are grateful to Turk Demirdokum A.Ş. the leading refrigerator company of Turkey for the experimental data. The first author wishes to thank King Mongkut's University of Technology Thonburi (KMUTT) for providing him with a Post-doctoral fellowship. The forth author is indebted to the Thailand Research Fund and the National Research University Project for supporting this study.

\section{NOMENCLATURE}

$\begin{array}{ll}\mathrm{h}_{\text {num }} & \text { convective heat transfer coefficient, } \mathrm{W} / \mathrm{m}^{2} \mathrm{~K} \\ \mathrm{~m}_{\text {in }} & \text { mass flow rate, } \mathrm{kg} / \mathrm{s} \\ \mathrm{Q}_{\text {exp }} & \text { experimentally found thermal capacity, } \mathrm{W} \\ \mathrm{Q}_{\text {num }} & \text { thermal capacity, } \mathrm{W} \\ \mathrm{T}_{\text {in }} & \text { inlet temperature, } \mathrm{K} \\ \mathrm{T}_{\text {out }} & \text { outlet temperature, } \mathrm{K} \\ \mathrm{T}_{\text {surface }} & \text { radiator surface temperature, } \mathrm{K} \\ \mathrm{T}_{\text {surround }} & \text { surrounding air temperature, } \mathrm{K} \\ \mathrm{V}_{\text {in }} & \text { velocity inlet, } \mathrm{m} / \mathrm{s} \\ \exp & \text { experimental } \\ \text { in } & \text { inlet } \\ \text { num } & \text { numerical } \\ \text { out } & \text { outlet }\end{array}$

\section{REFERENCES}

[1] Calisir, T., Yazar, H. O., Baskaya, S. and Yucedag, S (2016). Experimental and numerical prediction of flow field around a panel radiator. International Scientific Journal Journal of Environmental Science 5.

[2] Embaye, M., Al-Dadah, R. K., and Mahmoud, S. (2016). Numerical evaluation of indoor thermal comfort and energy saving by operating the heating panel radiator at different flow strategies. Energy and Buildings, 121, 298308. 
[3] R.J. Ladumor, V. Y Gajjar, and K.K.Araniya, (2014). A review paper on analysis of automobile radiator. International Conference on Multidisciplinary Research \& Practice 1 388-393.

[4] Calisir, T., Baskaya, S., Yazar, H. O., and Yucedag, S. (2015). Parametric numerical investigation of heat transfer from convectors to improve efficiency of panel radiators. In ICHMT Digital Library Online. Begel House Inc.

[5] Kayastha, K. S. (2015). CFD simulation of heat transfer analysis of automobile radiator using helical tubes. International journal of engineering research and development, 11(1), 24-35.

[6] Embaye, M., Al-Dadah, R. K., and Mahmoud, S. (2015). Thermal performance of hydronic radiator with flow pulsation-Numerical investigation. Applied Thermal Engineering, 80, 109-117.

[7] Johansson, P. O., and Wollerstrand, J. (2010). Heat output from space heating radiator with add-on-fan blowers. In Excerpt from Proceedings the COMSOL Conference.

[8] Shi, H. L., Liu, Y., Shao, Y. Z., and Jin, Y. A. (2015, June). Optimization design of plate-type radiator. In International Conference on Computer Information Systems and Industrial Applications. Atlantis Press.

[9] Myhren, J. A., and Holmberg, S. (2009). Design considerations with ventilation-radiators: Comparisons to traditional two-panel radiators. Energy and buildings, 41(1), 92-100.

[10] Sarbu, I., and Sebarchievici, C. (2015). A study of the performances of low-temperature heating systems. Energy Efficiency, 8(3), 609-627.

[11] Aydar, E., and Ekmekci, I. (2012). Thermal efficiency estimation of the panel type radiators with CFD analysis. Journal of Thermal Science and Technology, 32, 63-71.

[12] Salvio Chacko, D., Shome, B., Kumar, V., Agarwal, A. K., and Katkar, D. R. Numerical Simulation for Improving Radiator Efficiency by Air Flow Optimization.

[13] Sevilgen, G., and Kilic, M. (2011). Numerical analysis of air flow, heat transfer, moisture transport and thermal comfort in a room heated by two-panel radiators. Energy and Buildings, 43(1), 137-146.

[14] Shati, A. K. A., Blakey, S. G., \& Beck, S. B. M. (2011). The effect of surface roughness and emissivity on radiator output. Energy and buildings, 43(2-3), 400-406.

[15] Arslanturk, C., and Ozguc, A. F. (2006). Optimization of a central-heating radiator. Applied energy, 83(11), 1190-1197.

[16] Menéndez-Díaz, A., Ordóñez-Galán, C., Bouza-Rodríguez, J. B., and Fernández-Calleja, J. J. (2014). Thermal analysis of a stoneware panel covering radiators. Applied energy, 131, 248-256.

[17] Brady, L., Abdellatif, M., Cullen, J., Maddocks, J., and Al-Shamma'a, A. (2016). An investigation into the effect of decorative covers on the heat output from LPHW radiators. Energy and Buildings, 133, 414-422.

[18] Kılıç, M., Sevilgen, G., and Mutlu, M. (2014). Three-Dimensional Numerical Analysis of Thermal Output of a Steel Panel Radiator. In Progress in Exergy, Energy, and the Environment (pp. 585-593). Springer, Cham.

[19] Jahanbin, A., and Zanchini, E. (2016). Effects of position and temperature-gradient direction on the performance of a thin plane radiator. Applied Thermal Engineering, 105, 467-473.

[20] Beck, S. B., Blakey, S. G., and Chung, M. C. (2001). The effect of wall emissivity on radiator heat output. Building Services Engineering Research and Technology, 22(3), 185-194.

[21] Khalifa, A. J. N. (2001). Natural convective heat transfer coefficient-a review: I. Isolated vertical and horizontal surfaces. Energy conversion and management, 42(4), 491-504.

[22] Khalifa, A. J. N. (2001). Natural convective heat transfer coefficient-a review: II. Surfaces in two-and threedimensional enclosures. Energy Conversion and Management, 42(4), 505-517.

[23] Demir, H., Dalkilic, A. S., Kürekci, N. A., Duangthongsuk, W., and Wongwises, S. (2011). Numerical investigation on the single phase forced convection heat transfer characteristics of TiO2 nanofluids in a double-tube counter flow heat exchanger. International Communications in Heat and Mass Transfer, 38(2), 218-228.

[24] Incropera, F. P., and DeWitt, D. P. (1996). Fundamentals of Heat and Mass Transfer. 4th edn John Wiley \& Sons. New York. 